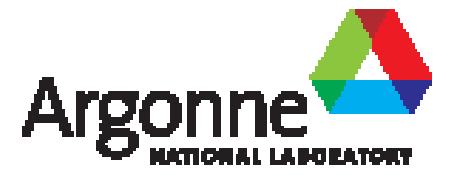

ANL/ESD-13/6

\author{
Large-scale Manufacturing of \\ Nanoparticulate-based Lubrication \\ Additives for Improved Energy Efficiency \\ and Reduced Emissions
}

Energy Systems Division 
About Argonne National Laboratory

Argonne is a U.S. Department of Energy laboratory managed by UChicago Argonne, LLC

under contract DE-ACD2-06CH11357. The Laboratory's maln taclity is outside Cnicago,

at 9700 South Cass Avenue, Argonne, Illinols 60439. For Information about Argonne

and its ploneering sclence and technology programs, see www. anl.gov.

Avallability of Thls Report

This report is avaliable, at no cost, at nttp://www. ostl.govibridge. It is also avallable

on paper to the U.S. Department of Energy and its contractors, for a processing fee, from:

U.S. Department of Energy

Omce of Sclentitic and Technical Information

P.O. Box 62

Oak Rldge, TN 37831-0062

phone (865) 576-8401

$\operatorname{tax}(865)$ 576-5728

reportsgadonis.ost.gov

Dicolaimer

Thls report was prepared as an account of work sponsored by an agency of the United States Government. Nelther the United states Government nor any agency thereot, nor UChicago Avoonne, LLC, nor any of their employees or oncers, makes any warranty, expreas or impled, or assumes any legsl lability or responelbility for the accuracy, compieteness, or usefuiness of any informaton, apparatus, product, or process decloeed, or represents that lts use would not intringe privately owned rights. Reference hereh to any apecific commerclal product, process, or service by trade name, trademart, manutacturer, or otherwise, does not necessarly consthute or imply It endorsement, recommendation, or Javoring by the Unlted States Govemment or ary apency thereot The views and opinlons of document authors expressed herein do not necessanly state or reflect those of the Unlled States Govemment or any agency thereot, Agonne National Laboratory, or UCAicago Avorne, LLC. 
ANL/ESD-13/6

\section{Large-scale Manufacturing of \\ Nanoparticulate-based Lubrication \\ Additives for Improved Energy Efficiency and Reduced Emissions}

by
Ali Erdemir
Energy Systems Division, Argonne National Laboratory

July 2013 
Final Technical Report

\section{Large-scale Manufacturing of Nanoparticulate- based Lubrication Additives for Improved Energy Efficiency and Reduced Emissions}

\section{Authors:}

Ali Erdemir, Argonne National Laboratory, Energy Systems Division, Argonne, IL 60439; Phone (630) 252-6571, Fax: (630) 252-5568, erdemir@anl.gov

Industrial Collaborator:

Valvoline/Ashland, 251 Yorkshire Blvd, Lexington, KY 40509 USA

DOE Award Number: CPS Agreement No. 17882

Project Period: 9/30/2008 - 9/30/2011 (extended to 12/31/2011)

Date of Report: July 2013 
Acknowledgment: This report is based upon work supported by the U.S. Department of Energy under Nanomanufacturing for the Energy Efficiency 2008 Research Call. Many dedicated scientists, engineers, technicians, and students have contributed to the project. In particular, Osman Eryilmaz and Kuldeep Mistry have played significant roles in various stages of the project and contributed toward its success. Valvoline personnel, including Frances Lockwood and Gefei Wei, were very helpful in guiding the project and supplying many types of lubricants for use in our studies. Primet Precision, Inc. helped in powder manufacturing and blending with lubricants. We also acknowledge Dr. Edward J. Daniels and William D. Ingle of Argonne for their help and guidance during the course of this project.

Disclaimer: Any findings, opinions, and conclusions or recommendations expressed in this report are those of the author(s) and do not necessarily reflect the views of the Department of Energy. 


\section{Table of Contents}

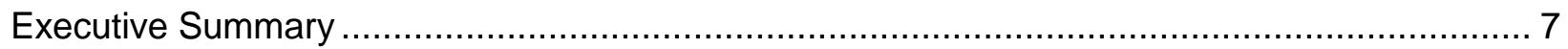

1. Introduction

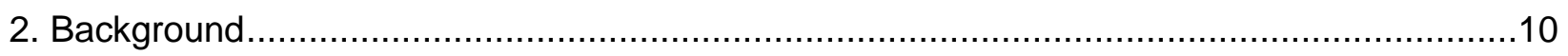

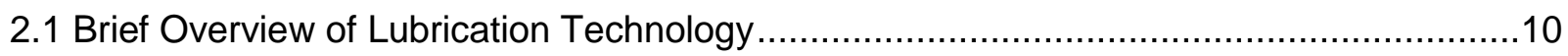

2.1.1 Solid Lubricants as Anti-friction and Anti-wear Additives .....................................11

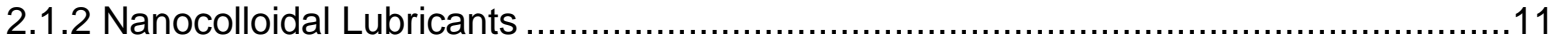

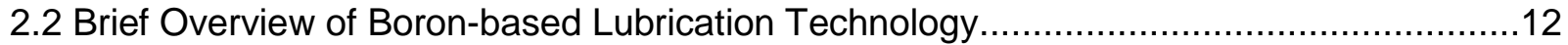

2.2.1 General Characteristics of Boron-based Lubricants .........................................12

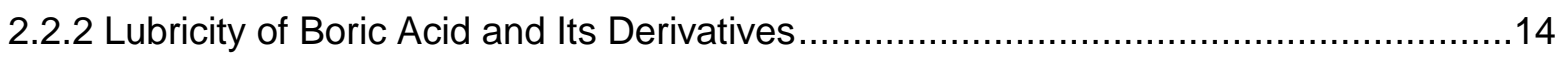

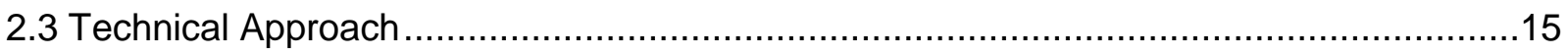

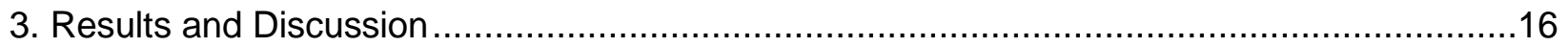

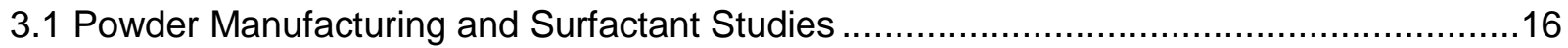

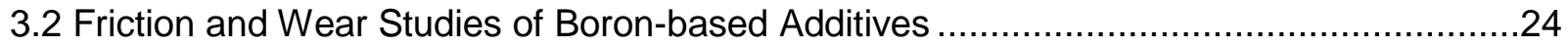

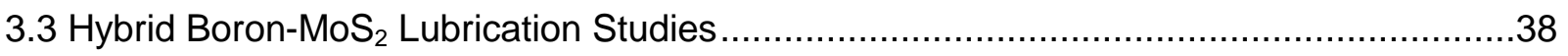

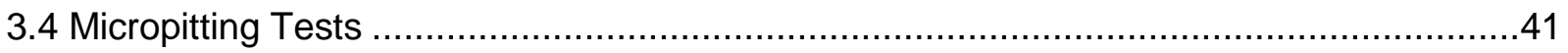

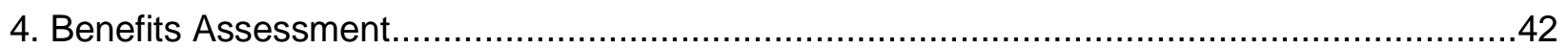

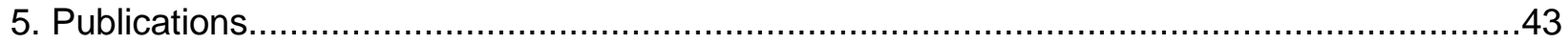

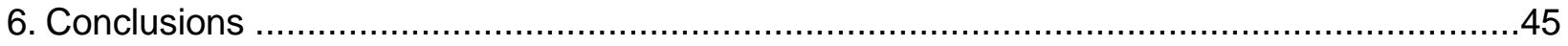

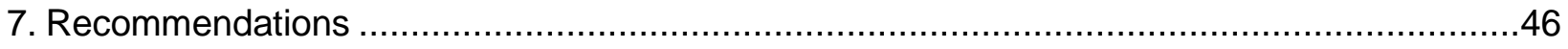

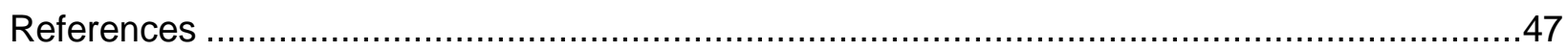




\section{Lists of Figures}

Figure 1. Triclinic layered crystal structure of boric acid. 13

Figure 2. Effect of boric acid particles on frictional behavior of a steel/steel test pair. 14

Figure 3. Effect of nanosize boron-based particulate additive (NBA) on friction coefficient of polyalphaolefin (PAO) base oil.

Figure 4. Ball milling machine used for downsizing of powders.

Figure 5. Particle size analyzer (top) and typical size distribution (bottom) of boric acid particles (at 5 wt.\% load) ball milled in PAO4 oil......

Figure 6. (a) Progression of size reduction during ball milling of borax powders and (b) colloidal dispersion in pure PAO oil at $1 \mathrm{wt} . \%$.

Figure 7. Effect of surfactant additive (SA) on size reduction of boric acid particles.

Figure 8. (a) Effect of surfactant type on size reduction of boron nitride during ball milling and (b) photo of boron nitride colloid prepared using surfactant 1 after 3 months on the shelf..............21

Figure 9. Photograph of (a) 5 wt.\% boric acid containing PAO4 alone and (b) 5 wt.\% boric acid with $1 \mathrm{wt} \%$ STO-MO surfactant in PAO4 at $100^{\circ} \mathrm{C}$.

Figure 10. TEM image and electron diffraction pattern of (a) initial and (b) 40 hour ball-milled boron nitride powder

Figure 11. Blending of a fully formulated synthetic oil with $5 \%$ of milled boric acid in canola oil, modified canola oil, and soybean oil....

Figure 12. (a) Friction coefficient for cylinder and flat specimen versus number of cycles and (b) wear after testing under different lubricated condition at an applied load of $325 \mathrm{~N}$.

Figure 13. Field emission SEM images of worn surfaces after test in (a) pure PAO and (b) surfactant-functionalized boric acid containing PAO.

Figure 14. General XPS spectra of tribofilms (i.e., protective boundary film) formed on various surfaces during tests in pure PAO4, PAO4 + STO-MO, PAO4 + boric acid, and PAO4 + boric acid + STO-MO. .28

Figure 15. XPS peaks for tribofilm compounds resulting from the testing of (a) 5 wt.\% boric acid alone in PAO4 and (b) 5 wt.\% boric acid with surfactant in PAO4 on steel surfaces. .29

Figure 16. AES profile diagram of (a) 5 wt.\% boric acid in PAO4 and (b) 5 wt.\% boric acid with 1 wt.\% surfactant in PAO4 on steel surfaces. 30

Figure 17. Friction and wear behavior of PAO4 oil (a) without and (b) with boric acid additive. .31

Figure 18. Friction and wear behavior of PAO4 oil with and without boron nitride additive. .......32

Figure 19. (a) Coarse and (b) high-resolution TEM images, and (c) XPS spectra taken from the 
tribofilm formed in tests of PAO4 and boron nitride.

Figure 20. Chemical depth profiling and imaging of the sliding surfaces determined by TOFSIMS, confirming high boron concentration near the surface.

Figure 21. Effect of nano-boron additive on wear performance of Valvoline's 5 W30 oil without ZDDP anti-wear additive

Figure 22. Effect of nano-boron additive on wear performance of Valvoline's 5W30 oil without MoDTC anti-friction additive.

Figure 23. XPS spectrum and chemical quantification of species within tribofilm that resulted from a hybrid $\mathrm{MoS}_{2}+$ boric acid nanolubricant.

Figure 24. Boron and molybdenum chemical species identified using high-resolution XPS within the tribofilm, which resulted from hybrid $\mathrm{MoS}_{2}+$ boric acid based nanolubricants.

Figure 25. Proposed protective tribofilm model for hybrid $\left(\mathrm{MoS}_{2}+\right.$ boric acid) nanolubricant on sliding steel surfaces.

Figure 26. Photo and general layout of the PCS micropitting (gear) test machine and test conditions used in our evaluation.

Figure 27. Images of test rollers used in micropitting (gear) tests.

Figure 28. Accelerometer noise levels from Valvoline $75 \mathrm{~W} 90$ and the same oil blended with our nano-boron additive. 


\section{List of Tables}

Table 1. XPS quantification (in atomic \%) of tribofilms formed on flat samples.................28

Table 2. Scuffing and friction performance of different types of oils with and without boron

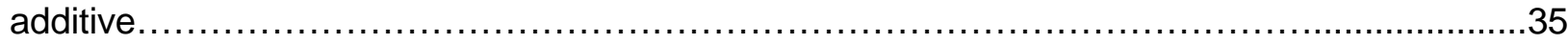

Table 3. Friction and wear results and comments on reciprocating tests using various lubricants

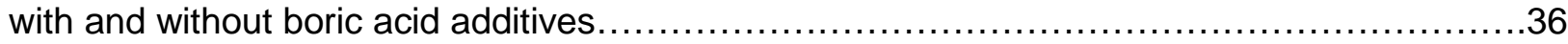

Table 4. Wear performance of a VG220 gear oil with and without $\mathrm{MoS}_{2}$ and boric acid..........39 


\section{Executive Summary}

This project was funded under the Department of Energy (DOE) Lab Call on Nanomanufacturing for Energy Efficiency and was directed toward the development of novel boron-based nanocolloidal lubrication additives for improving the friction and wear performance of machine components in a wide range of industrial and transportation applications. Argonne's research team concentrated on the scientific and technical aspects of the project, using a range of state-of-the art analytical and tribological test facilities. Argonne has extensive past experience and expertise in working with boron-based solid and liquid lubrication additives, and has intellectual property ownership of several. There were two industrial collaborators in this project: Ashland Oil (represented by its Valvoline subsidiary) and Primet Precision Materials, Inc. (a leading nanomaterials company). There was also a sub-contract with the University of Arkansas.

The major objectives of the project were to develop novel boron-based nanocolloidal lubrication additives and to optimize and verify their performance under boundary-lubricated sliding conditions. The project also tackled problems related to colloidal dispersion, larger-scale manufacturing and blending of nano-additives with base carrier oils. Other important issues dealt with in the project were determination of the optimum size and concentration of the particles and compatibility with various base fluids and/or additives. Boron-based particulate additives considered in this project included boric acid $\left(\mathrm{H}_{3} \mathrm{BO}_{3}\right)$, hexagonal boron nitride (h-BN), boron oxide, and borax. As part of this project, we also explored a hybrid $\mathrm{MoS}_{2}+$ boric acid formulation approach for more effective lubrication and reported the results.

The major motivation behind this work was to reduce energy losses related to friction and wear in a wide spectrum of mechanical systems and thereby reduce our dependence on imported oil. Growing concern over greenhouse gas emissions was also a major reason. The transportation sector alone consumes about 13 million barrels of crude oil per day (nearly 60\% of which is imported) and is responsible for about $30 \%$ of the $\mathrm{CO}_{2}$ emission. When we consider manufacturing and other energy-intensive industrial processes, the amount of petroleum being consumed due to friction and wear reaches more than 20 million barrels per day (from official energy statistics, U.S. Energy Information Administration). Frequent remanufacturing and/or replacement of worn parts due to friction-, wear-, and scuffing-related degradations also consume significant amounts of energy and give rise to additional $\mathrm{CO}_{2}$ emission. Overall, the total annual cost of friction- and wear-related energy and material losses is estimated to be rather significant (i.e., as much as $5 \%$ of the gross national products of highly industrialized nations) [1].

It is projected that more than half of the total friction- and wear-related energy losses can be recovered by developing and implementing advanced friction and wear control technologies. In transportation vehicles alone, $10 \%$ to $15 \%$ of the fuel energy is spent to overcome friction. If we can cut down the friction- and wear-related energy losses by half, then we can potentially save up to 1.5 million barrels of petroleum per day. Also, less friction and wear would mean less energy consumption as well as less carbon emissions and hazardous byproducts being generated and released to the environment. New and more robust anti-friction and -wear control technologies may thus have a significant positive impact on improving the efficiency and environmental cleanliness of the current legacy fleet and future transportation systems. Effective control of friction in other industrial sectors such as manufacturing, power generation, mining and oil exploration, and agricultural and earthmoving machinery may bring more energy 
savings. Therefore, this project was timely and responsive to the energy and environmental objectives of DOE and our nation.

In this project, most of the boron-based materials with known and potential anti-friction and -wear properties have been manufactured as colloidal additives and tested for their effectiveness in controlling friction and wear. Unlike other anti-friction and -wear additives, which consist of zinc, molybdenum, sulfur, phosphorus, and even chlorine, lubricious boron compounds considered in this project are made of boron, oxygen, nitrogen, and hydrogen, which are more environmentally benign. Among others, boric acid is a natural mineral (known in mineralogy as "sassolite"). Based on our earlier exploratory research, it was found to offer the best overall prospect in terms of performance improvements, environmental friendliness, and ease of manufacturing and, hence, cost effectiveness. Hexagonal boron nitride and borax also offered good prospects for improving the tribological properties of lubricated sliding surfaces. Boron oxide particles were found to be rather hard and somewhat abrasive and, hence, were not considered beyond the initial screening studies. In our bench-top tribological evaluation, we also demonstrated that those additives which worked well with engine oils could work equally well with very common gear oils. When added at appropriate concentrations, such gear oils were found to provide significant resistance to micropitting and scuffing failures in bench-top tribological test systems. Their traction coefficients were also reduced substantially and their scuffing limits were improved considerably. Such impressive tribological behavior of boronbased additives may have been due to their high chemical affinities to interact with sliding contact surfaces and to form slick and protective boundary films. Indeed, our surface studies have confirmed that most of the boron-based nanoparticulate additives prepared in our project possess a strong tendency to form a boron-rich boundary film on sliding contact surfaces. It is believed that the formation of such slick and highly durable boundary films is perhaps one of the fundamental reasons for their superior anti-friction, -wear, and -scuffing performance.

Boron-based additives developed under this project have shown potential to reduce or replace the uses of environmentally unsafe sulfur- and phosphorus-bearing anti-wear and -friction additives, such as zinc dialkyl dithiophosphate (ZDDP) and molybdenum dialkyl dithiocarbamate (MoDTC), in current lubricating oils. Because ZDDP and MoDTC were suspected of adversely impacting the performance of after-treatment catalysts in current engines, the Environmental Protection Agency (EPA) and other regulatory agencies are demanding that the concentrations of these catalysts in current oils be curtailed drastically. The boron-based nano-additives developed in this project may help reduce the use of ZDDP and MoDTC additives and, hence, help ease the poisoning effects on after-treatment catalysts. When used as lubricity additives, these boron additives can chemically interact with sliding or contacting surfaces and form a protective and slick boundary film, which can, in turn, help reduce friction and wear and increase resistance to scuffing. In the cases of traditional anti-friction and -wear additives mentioned, such protective boundary films result from phosphorus, sulfur, and other elements in the additive package, and again they have been under increased scrutiny in recent years, mainly because of their adverse effects on after-treatment devices.

Overall, the boron-based nano-additive technology of this project was shown to hold promise for a broad range of industrial and transportation applications where lower friction and higher resistance to wear and scuffing are needed. Due to more stringent operating conditions of modern machinery, rolling, rotating, and sliding components have been failing to meet the projected lifetimes, mainly because of failures related to mechanical wear, corrosion, and scuffing. The novel boron-based additive technology developed under this project may help such machine components to function reliably by cutting down the friction and wear losses and by increasing resistance to scuffing. 


\section{Introduction}

The energy efficiency, durability, and environmental compatibility of all kinds of moving mechanical systems depend on the effectiveness of the lubricants being used on their rolling, rotating, reciprocating, and sliding surfaces. In particular, progressive wear and fatigue due to inadequate lubrication is one of the most serious root causes of component failure. Poor lubrication can also cause significant energy losses in moving mechanical systems, mainly because of higher friction or traction [2]. Literally, all moving components in a mechanical system rely on effective lubricants for smooth and long-lasting operation. Besides improving friction and wear performance, lubricants also carry away heat and wear particles from the contact interfaces; prevent oxidation, corrosion, and varnish and deposit formation on sliding surfaces; improve resistance to temperature extremes; neutralize combustion products; and most important, help convert and transmit power safely and smoothly. Therefore, lubricants play a vital role in the mobility and industrial activity of humanity.

In response to the Department of Energy (DOE) Lab Call on Nanomanufacturing for Energy Efficiency in 2008, Argonne National Laboratory prepared and submitted a research proposal primarily focused on the possibility of large-scale manufacturing and industrial uses of boronbased nanolubrication additives. Specifically, Argonne in collaboration with Ashland Oil (represented by its Valvoline subsidiary) and Primet Precision Materials, Inc. (a leading nanomaterials company) proposed to develop boron-based nanocolloidal lubrication additives for use in a wide range of transportation and industrial applications. Based on the results of initial exploratory research, some of these additives looked promising for improving the performance, efficiency, and durability of rolling, rotating, and sliding mechanical components. Furthermore, compared to other particulate-based additive technologies, boron-based products offered the possibility of replacing or reducing the uses of environmentally unsafe sulfur- and phosphorus-bearing additives such as zinc dialkyl dithiophosphate (ZDDP), which has a poisoning effect on after-treatment catalysts. These additives are also the sources of undesirable heavy metals and sulfated ash, phosphorus, and sulfur (SAPS) in current oils. In this project, we aimed to further optimize, test, and demonstrate the superior anti-friction and wear properties of these additives by using a variety of bench-top tribological machines.

Because of the vital role of lubricants in the efficiency and reliability of machine components combined with societal mobility and industrial activity, the lubricant industry has enjoyed steady growth since the beginning of the $20^{\text {th }}$ century. Currently, more than 40 million metric tons of lubricants are used for various purposes. Engine oils account for the largest lubrication activity in the world, and that market is expected to further increase due to increasing motor vehicle ownership, especially in developing countries like China and India. Industrial lubricants represent the second largest and the fastest growing segment in the lubrication field due to high demands in the manufacturing segment. Nearly $25 \%$ of the world lubricant production is consumed by the U.S. alone, but the overall market size of all industrial activities that rely on effective lubrication is in the trillion dollar range (since almost all moving mechanical systems used in these activities rely on lubrication for long life and smooth operation). Major lubricants that are in use today are largely petroleum- and synthetic-based, and they are mostly applied as engine oils, process oils, hydraulic fluids, metal-forming and -cutting fluids, and various greases. There is no doubt that demands for high-performance and environmentally friendly lubricants will continue to increase in coming years; however, because of the increasing cost of petroleum and tougher environmental regulations, the lubricant companies have lately been looking into novel, cheaper, and environmentally friendlier alternatives, including nano-solid lubrication additives. 


\section{Background}

\subsection{Brief Overview of Lubrication Technology}

The history of lubricants and lubrication practices for man-made devices reaches back thousands of years. Through the $19^{\text {th }}$ century, key lubricants have included water, vegetable oils (like olive oil), and animal fats (like lard or tallow). With the introduction of internal combustion engines around the 1900 s, petroleum-based products became increasingly more popular due to their much superior and longer-lasting lubrication capabilities. Subsequently, synthetic lubricants were introduced into the marketplace and used extensively to achieve much greater performance and durability in engines and other demanding industrial applications. Since the 1950s, lubricants have also been mixed with a variety of chemical additives to achieve much higher lubricity and wear performance. In today's modern lubricants, additives play a major role in controlling friction and wear losses and increasing scuff resistance of sliding surfaces. These additives may account for 10 to $15 \%$ of the total volume of all formulated oils. One of the key additives, ZDDP, is used in almost all types of engine and other industrial lubricants due to its outstanding anti-wear, extreme pressure (EP), and anti-oxidation characteristics, especially under severe application conditions. Without it, the durability and performance of these lubricants are severely impaired. ZDDP forms a highly durable and protective boundary film on most sliding surfaces and thus prevents micro-welding or seizure under severe loading conditions. Another important additive is molybdenum dialkyl dithiocarbamate, or MoDTC, used primarily to achieve lower friction on sliding surfaces. Previous research has shown that this additive results in the formation of a layered $\mathrm{MoS}_{2}$-like boundary film and thus provides much lower friction [3]. Some of the boron-based nanolubrication additives (i.e., boric acid and hexagonal boron nitride) being proposed here also have layered structures and can thus provide low friction and wear to lubricated sliding surfaces.

The current anti-friction and -wear additives mentioned above were found to contribute to undesirable SAPS problems and to impair the performance of after-treatment devices of modern engines [4]. In particular, ZDDP has been found to poison the catalysts (especially the $\mathrm{NO}_{\mathrm{x}}$ catalyst in diesels) in the emission control devices of diesel engines. Furthermore, ZDDP and MoDTC contain heavy metals (Mo and $\mathrm{Zn}$ ) besides sulfur and phosphorus, and hence they may also contribute to the particulate emissions. Sulfur in these additives may also react with moisture in the combustion chamber and form acids that may cause additional problems in engines. Therefore, there is a growing need for new and more effective lubrication strategies in order to meet the increasingly more stringent operating and environmental requirements of future engine systems. The boron-based colloidal lubrication additives of this project offer good prospects for future lubrication applications.

Component failures due to inadequate lubrication may range from nanoscale fretting at asperity levels to micro- and macro-scale abrasion and spallation due to severe wear, scuffing, and contact fatigue. These mechanisms are very typical of most sliding and/or rolling surfaces operating under abrasive or boundary-lubricated sliding conditions (which represent the most severe contact situation). The boundary regime typically involves low speeds, low-viscosity oils, and high temperatures and loads. Obviously, under such severe contact conditions, oil film thickness (in fact a few molecules thick) is much smaller than the composite surface roughness, and hence, the surface asperities are in frequent contact or collision with each other in this regime of sliding. As a result, friction and wear losses are rather significant in the boundary regime. In fact, most of the wear debris particles are generated in this regime under the influence of adhesive, abrasive, and oxidative interactions. Obviously, a low-shear boundary film made of the boron-based solid lubricants may have a positive impact on friction and wear of 
surfaces when the component is operating under the boundary lubrication regime. In the full film lubrication regime, friction is mainly due to viscous shear, and hence, the viscosity of oils becomes the most important factor. The mixed-lubrication regime involves both viscous shearing of the lubricating oils and intermittent contacts between surface asperities in the opposite side. Overall, in lubricated mechanical systems, physical, chemical, and mechanical events that take place in the boundary lubrication regime impact much of the friction- and wearrelated energy and materials losses, and despite intense work over the past several decades, there are no easy solutions to these problems. Application of hard coatings over sliding contact surfaces appears to help retard the wear process, but frictional losses are yet to be addressed, therefore, the use of low-friction colloidal additives may certainly help.

\subsubsection{Solid Lubricants as Anti-friction and Anti-wear Additives}

In view of the above-mentioned critical friction, wear, and environmental issues resulting from the uses of current lubrication technologies, it looks as though combining the lubrication potential of solid lubricants with those of liquid ones may present unique opportunities for the formulation of future oils. Some solid lubricants are extremely effective in reducing friction and wear under severe contact conditions, where liquid lubricants often fail or lose their effectiveness. These solids are also resistant to elevated temperatures and corrosive/oxidative attacks. Accordingly, a number of lubricants containing fine (micro-scale) powders of certain solids have already been prepared and used to achieve better friction and wear properties in industrial applications [5]. For example, micro-powders of molybdenum disulfide $\left(\mathrm{MoS}_{2}\right)$, graphite, hexagonal boron nitride $(\mathrm{h}-\mathrm{BN})$, boric acid $\left(\mathrm{H}_{3} \mathrm{BO}_{3}\right)$, and poly-tetrafluoroethylene (PTFE) have all been mixed with greases to enhance their lubrication properties. Colloidal dispersion of these solid lubricants in mineral and/or synthetic-based oils has also been explored [5-7].

The high chemical inertness of some solid lubricants $\left(\mathrm{MoS}_{2}\right.$, graphite, h-BN, PTFE, etc.) makes it very difficult to disperse them homogeneously in the carrier oils. Moreover, penetration of micro-scale particles to very tight spacing between the mating surfaces is very difficult. Most often, the particles tend to accumulate in and around the contact spots and thus even block the easy flow of liquid lubricants to these critical spots. Overall, most of the available coarse particulate lubrication products do not adequately address the issues around the ever increasing boundary regime for friction and wear, but their nanoscale counterparts (ranging in size from 10 to $100 \mathrm{~nm}$ ) may overcome some of these problems without any adverse impacts.

\subsubsection{Nanocolloidal Lubricants}

During the last two decades or so, great strides have been made in the manufacturing of nanoparticles or nanopowders using both bottom-up and top-down approaches. Most of the self-lubricating solids are now available in nanopowder forms from various industrial sources. The finer solids (i.e., 1 to $30 \mathrm{~nm}$ range) are mostly made of nanostructured carbons, like $\mathrm{C}_{60}$, nanotubes, nanofibers, nano-onions, nanodiamonds, graphene, etc., while intermediate range lubricants (30 to $100 \mathrm{~nm}$ ) are made of inorganic solids, such as $\mathrm{MoS}_{2}, \mathrm{WS}_{2}, \mathrm{~h}-\mathrm{BN}$, and pure metals (gold, silver, tin, bismuth, etc.). Also, $\mathrm{WS}_{2}$ and $\mathrm{MoS}_{2}$ can be synthesized in the form of fullerene-like nanoparticles down to tens of nanometers, and hence, they are often referred to as "inorganic fullerenes" [5]. With the increased availability of these nanoscale solid lubricants, many researchers have recently been exploring their usefulness as potential anti-friction and wear additives in oils and greases. Most of the nanomaterials mentioned above require manufacturing by very complex bottom-up approaches. In most cases, these approaches 
involve numerous chemical synthesis routes (e.g., gas phase chemical processing, combustion and/or plasma synthesis, catalytic decomposition, and sonochemistry). Unfortunately, some approaches turned out to be very expensive and difficult to scale up for large-volume and lowcost lubrication applications. These approaches were also found to generate large amounts of waste or hazardous by-products to deal with after the manufacturing processes.

As can be deduced from the discussion above, at the start of this project, a large body of active research existed in the manufacturing and testing of various nanoparticles for lubrication purposes. However, some skepticism existed on their scalability, cost-competitiveness, environmental friendliness, and consumer acceptance. In particular, high cost and environmental issues with some of the carbon-based nanomaterials were seen as potential hurdles for large-scale applications. Among the many solid lubricants mentioned, we believe that $\mathrm{WS}_{2^{-}}$and $\mathrm{MoS}_{2}$-based nanolubricants offer promise for large-scale commercial applications; however, their heavy metal and sulfur contents might contribute to SAPS and may pose some other problems, such as adverse impact on after-treatment devices (due to the sulfur content). Also, due to their high molecular weights, keeping them in colloidal dispersion for a long time may not be so easy; as a consequence, settlement/separation might be a problem. To circumvent some of these problems, in this project, we also explored the feasibility of developing a hybrid boron- $\mathrm{MoS}_{2}$-based lubrication approach. Such a hybrid system might provide some beneficial synergistic effects over a broad range of application conditions.

\subsection{Brief Overview of Boron-based Lubrication Technology}

Physically, boron is a light element with high hardness and possesses both metallic and nonmetallic attributes (hence, it is often considered as a metalloid). Chemically, boron has a strong tendency to react with many elements and to form covalently bonded organic/inorganic compounds. Ionic and metallic bonding is also possible as in a variety of metal borides and borates. Some compounds are used by industry in large quantities, especially in glass-making, ceramics/enamels, textiles, detergents, medicine, pest control, fire retardants, and agricultural fertilizers. Cubic boron nitride, boron carbide, and transition metal borides are known for their extreme hardness and high resistance to wear and corrosion; hence, they are often used in the making of tool inserts, cermets, and wear protective coatings. In the field of lubrication, h-BN is well-recognized for its slippery nature and used extensively as a solid lubricant in metal-forming operations involving high temperatures [7]. Boric acid $\left(\mathrm{H}_{3} \mathrm{BO}_{3}\right)$ represents another lamellar boron compound which can also reduce friction and wear in many tribological applications [8, 9]. Furthermore, many other boron compounds (especially borate esters) have been synthesized and used for lubrication purposes in the past. In fact, the chemistry of organoboron compounds is very rich, and several of them have been tested for their extreme pressure and antioxidation/-corrosion potentials in oils and greases [10-13]. In the following sub-sections, the general characteristics of solid lubricant h-BN and $\mathrm{H}_{3} \mathrm{BO}_{3}$ are summarized briefly first, and then the types of boron-based nanolubrication additives to be explored in this project are reviewed in greater detail. The major emphasis is on boric acid and its lubricity as micro- and nanocolloidal additives in oils.

\subsubsection{General Characteristics of Boron-based Lubricants}

Hexagonal boron nitride is a well-known solid lubricant and used by industry for a variety of applications. Its structure is similar to that of graphite, but unlike graphite, it is white (hence, occasionally referred to as "white graphite"). Its atomic layers are made of two-dimensional arrays of strongly (covalently) bonded boron and nitrogen atoms. As in graphite, bonding between the atomic layers is van der Waals type and, hence, relatively weak. In tribological 
testing, these layers slide over one another and thus provide low friction. When tested in open air, the friction coefficient of $\mathrm{h}-\mathrm{BN}$ is $0.2-0.3$. In high-temperature manufacturing operations, h-BN exhibits excellent chemical stability and high resistance to oxidation; hence, for many years it has been used as a release agent in a variety of extreme temperature applications where no other lubricants are effective.

In past years, h-BN has also been tried as a microcolloidal additive in oils and greases, and at concentrations of $1 \mathrm{wt}$ \% or more, it has displayed excellent resistance to wear [7]. However, there is little or no experimental work dealing with the lubrication behavior of nano-h-BN dispersed in oils or greases, even though various types of nanotubes, sheets, and nanopowders have been produced from h-BN in recent years [14]. One of the goals of this project was to conduct a systematic study on the tribological behavior of nano-h-BN structures and to determine their potential as nanocolloidal lubrication additives.

Boric acid $\left(\mathrm{H}_{3} \mathrm{BO}_{3}\right)$ is another boron-based layered naturally-occurring solid lubricant. It is known as "sassolite" in mineralogy textbooks. Just like h-BN, it is made up of sheets of strongly bonded boron, hydrogen, and oxygen atoms. There are two major crystalline forms of boric acid: metaboric acid $\left(\mathrm{H}_{2} \mathrm{O} \cdot \mathrm{B}_{2} \mathrm{O}_{3}\right.$ or $\left.\mathrm{HBO}_{2}\right)$ and orthoboric acid $\left(3 \mathrm{H}_{2} \mathrm{O} \cdot \mathrm{B}_{2} \mathrm{O}_{3}\right.$ or $\left.\mathrm{H}_{3} \mathrm{BO}_{3}\right)[8,9]$. Orthoboric acid is the most common form and may easily result from the hydration of boric oxide $\left(\mathrm{B}_{2} \mathrm{O}_{3}\right)$. Metaboric acid crystallizes in three forms: orthorhombic or a-metaboric acid, monoclinic or $ß-$ metaboric acid, and cubic or $\mathrm{y}$-metaboric acid. Among all these boric acid types, orthoboric and orthorhombic metaboric acids exhibit layered-crystal structures, but since the orthoboric acid is the most common, it was one of the major boron compounds evaluated for its friction and wear properties in this project.

In the triclinic crystal structure of boric acid, boron, oxygen, and hydrogen atoms are strongly bonded to one another to form extensive atomic layers that are parallel to the basal plane of the crystal (see Fig. 1). There are four boric acid molecules in each unit cell. In atomic layers, each boron cation is bonded to three oxygen anions to form the triangular $\mathrm{BO}_{3}$ groups. Bonding between boron and oxygen is predominantly covalent, but some ionic characters may also exist. Hydrogen bonds link the planar $\mathrm{BO}_{3}$ groups together. Bonding between the atoms lying on the same plane is of the covalent/ionic and hydrogen type. The layers are

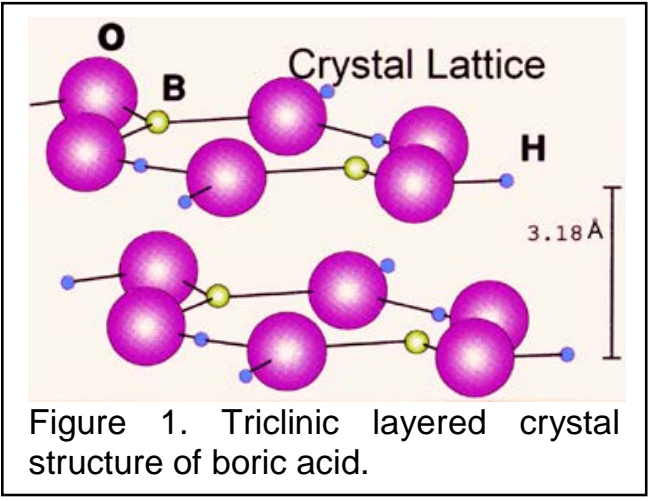
$0.318 \mathrm{~nm}$ apart and held together by weak van der Waals forces.

Boric acid is a mild, non-toxic solid. Diluted water solutions of boric acid are often used to wash eyes. Boric acid is also used as an antiseptic, insecticide, flame retardant, and food preservative. The EPA has established that boric acid is benign and is not classified as a pollutant under the Clean Water Act. However, in Europe, boric acid is placed in a somewhat different chemical classification. For product containing $<5 \%$ boric acid, there are no special labeling requirements, but the Materials Safety Data Sheet (MSDS) may need to indicate the presence of a "substance of very high concern." Boric acid is available in very large quantities for all types of industrial applications, and it is considered low cost (i.e., one metric ton of boric acid is around $\$ 800$ [15]). 


\subsubsection{Lubricity of Boric Acid and Its Derivatives}

As mentioned above, $\mathrm{H}_{3} \mathrm{BO}_{3}$ and $\alpha-\mathrm{HBO}_{2}$ are self-lubricating due to their layered-crystal structures; hence, they can afford very low friction and wear coefficients to sliding tribological interfaces. Figure 2 shows how feeding boric acid powders to a sliding contact interface of a steel test pair decreased friction from about 0.8 to less than 0.05 . The lubrication mechanism of the bulk and thin film forms of boric acid is similar to that of the other known lamellar solids. Specifically, under shear stresses, atomic sheets of $\mathrm{H}_{3} \mathrm{BO}_{3}$ (see Fig. 1) can align themselves parallel to the direction of relative motion and then slide over one another with relative ease to provide the low friction coefficient shown in Fig. 2 [8]. In previous studies [5,8,9], boric acid was found to smear and bond strongly to the sliding surfaces of metallic and ceramic materials, mainly because of its multiple bond-forming capabilities (i.e., ionic, covalent, hydrogen, and van der Waals).

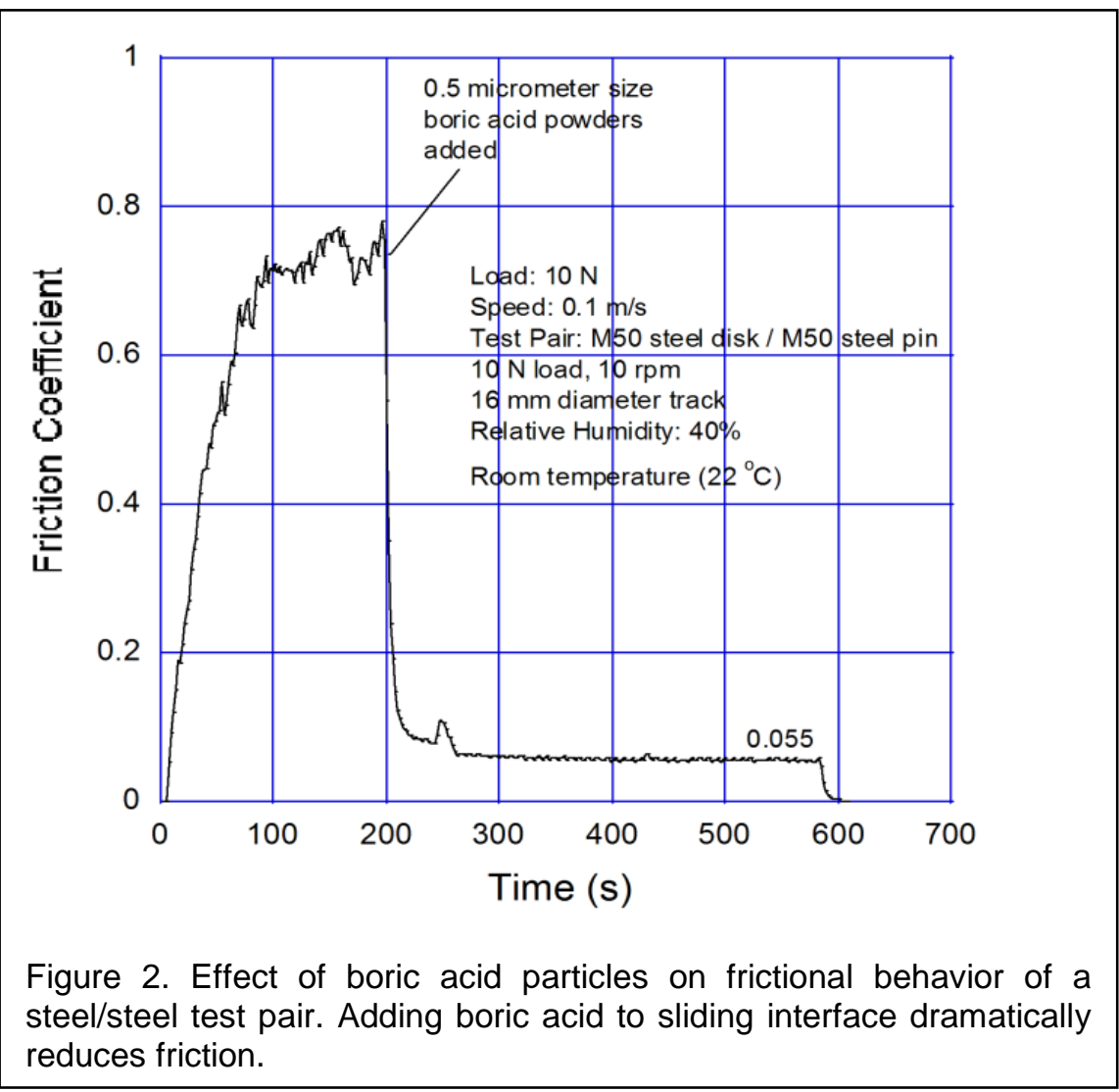

Figure 3 shows the lubrication performance of boric acid particles dispersed in base oils. In this figure, lubrication performance is determined through friction coefficient measurements that were taken with a pin-on-disk machine, which consists of a stationary top-mounted steel pin that rubs against a unidirectional rotating steel disk or flat. The pins can be either flat or hemispherically tipped (typically, the pins have a $127-\mathrm{mm}$ radius ground on one of the faces). The lubricants are applied to the disk surface, and the pins are rubbed against the disk. A load is applied to the pin by using dead weights. For the specific tests performed, $20 \mathrm{~N}$ loads were used, and the sliding velocity of the rotating disk was adjusted to give linear velocities of 0.01 
and $0.1 \mathrm{~m} / \mathrm{s}$. Tests were run at room temperature and in open air whose relative humidity was varied between $30 \%$ and $60 \%$.

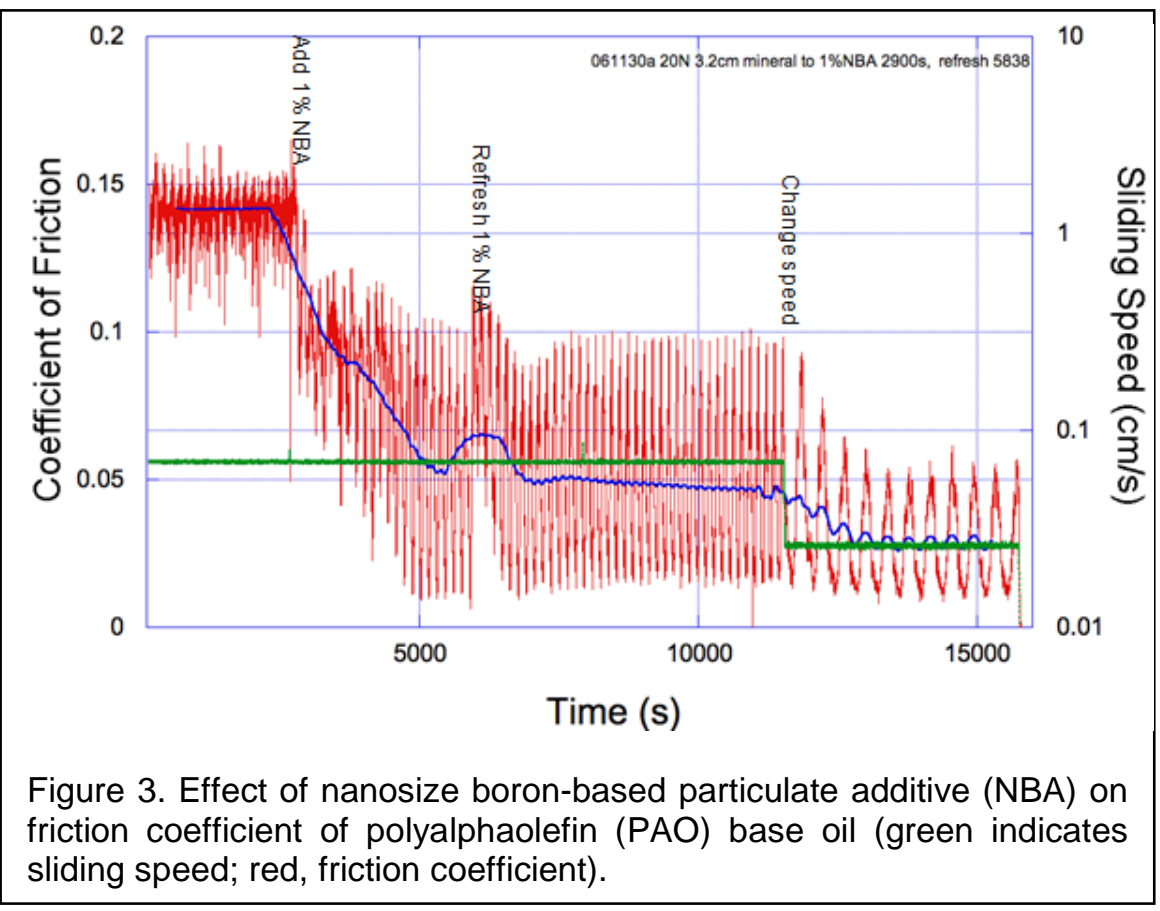

As shown in Fig. 3, with the use of base PAO on sliding steel surfaces, the average friction coefficient is $\sim 0.15$. However, when PAO is blended with $1 \mathrm{wt} . \%$ nanoparticle boric acid (NBA), the friction coefficient is reduced to 0.05 . Upon reduction of sliding speed toward the end of testing, the friction coefficient is further reduced, presumably due to the formation of a slick boron-rich boundary film. From a mechanistic point of view, during sliding contact, solid nanoparticles of boric acid are carried to the vicinity of the contact zone by liquid oil and then dragged into the contact interface. Upon entering the contact zone, they are smeared on rubbing surfaces as a very thin (a few nanometers thick) boundary film. Once formed, these boundary films can protect sliding surfaces against wear and reduce friction because of their shear properties. The molecules that make up these nanoparticles may possibly rearrange themselves in a plate-like boric acid structure to enhance the anti-friction and -wear properties of these sliding surfaces. Because of its protective nature, the boron-rich boundary film can also reduce wear [16].

\subsection{Technical Approach}

The major goals of this project were to develop and optimize a number of boron-based colloidal lubrication additives, to prepare and test samples, and to determine their tribological properties over a range of test conditions. Working consistently over the past two decades, the Argonne principal investigators have acquired vast knowledge and experience on boron-based solid lubrication technologies; in particular, $\mathrm{H}_{3} \mathrm{BO}_{3}$ has been proven to be very effective in reducing friction and wear of sliding contact surfaces under both dry and lubricated sliding conditions (see Figs. 2 and 3).

Further development and optimization of the manufacturing process for nanoparticles as well as their characterization and testing required an interdisciplinary approach encompassing relevant 
expertise and experience in materials science, colloidal chemistry, powder technology, and tribology. Argonne's research team (consisting of several materials scientists, mechanical engineers, chemists, and tribologists) concentrated on the scientific and technical aspects of the project using a range of state-of-the art analytical and tribological test facilities. The major tasks of the Argonne team included comprehensive lab studies to optimize lubricant performance and then validation of performance under more prototypical test conditions. We also initiated screening wear tests and post-test characterization using relevant microscopy and other analytical techniques. Initial work on boric acid and boron nitride mainly concentrated on microcolloidal products, which have worked quite well especially when mixed with greases. In this project, we focused our attention on the fabrication of nanocolloidal versions of boric acid and other boron-based products (such as boron nitride, borax, and boron oxide) because they also offered good prospects for applications in transportation and other industrial sectors.

\section{Results and Discussion}

\subsection{Powder Manufacturing and Surfactant Studies}

Boron-based compounds can be prepared in powder forms by a variety of well-established methods, including mechanical attrition or ball-milling, chemical precipitation, sonochemical synthesis from organoboron compounds, low-pressure gas condensation, and low-temperature evaporation of ethyl borates or methanol or ethanol solutions of boric acid into or through the lubricating oils. During Year 1, major activities included the production of powders and optimization of concentration and their dispersibility in carrier oils. These activities were primarily directed toward understanding of the relationship between various ball manufacturing conditions and powder size (and distribution), morphology, shape, and chemical and physical states of the end products. Mechanical attrition (ball milling and other similar crushing techniques) can reduce the size of macro- or microsized particles to the ranges of 50 to $500 \mathrm{~nm}$ rather easily. Accordingly, the Argonne team procured a lab-scale ball milling machine and performed extensive powder manufacturing studies to demonstrate that the end products would be technically feasible and economically viable. Initial lab studies were directed toward the manufacturing of boric acid powders using the ball milling machine shown in Fig. 4. Figure 5 shows the particle size analyzer and typical particle size distribution of boric acid particles (original size was $\approx 30 \mu \mathrm{m}$ ) after about 5 hours of ball milling. Figure $6 a$ shows the progression of particle size reduction for coarse borax powders (i.e., $\approx 20 \mu \mathrm{m}$ ) during a ball milling operation. Figure $6 \mathrm{~b}$ shows the colloidal dispersion of such particles in a carrier PAO oil. The nanopowders of boric acid are milky white, and when mixed with oils, they look milky white as well. 

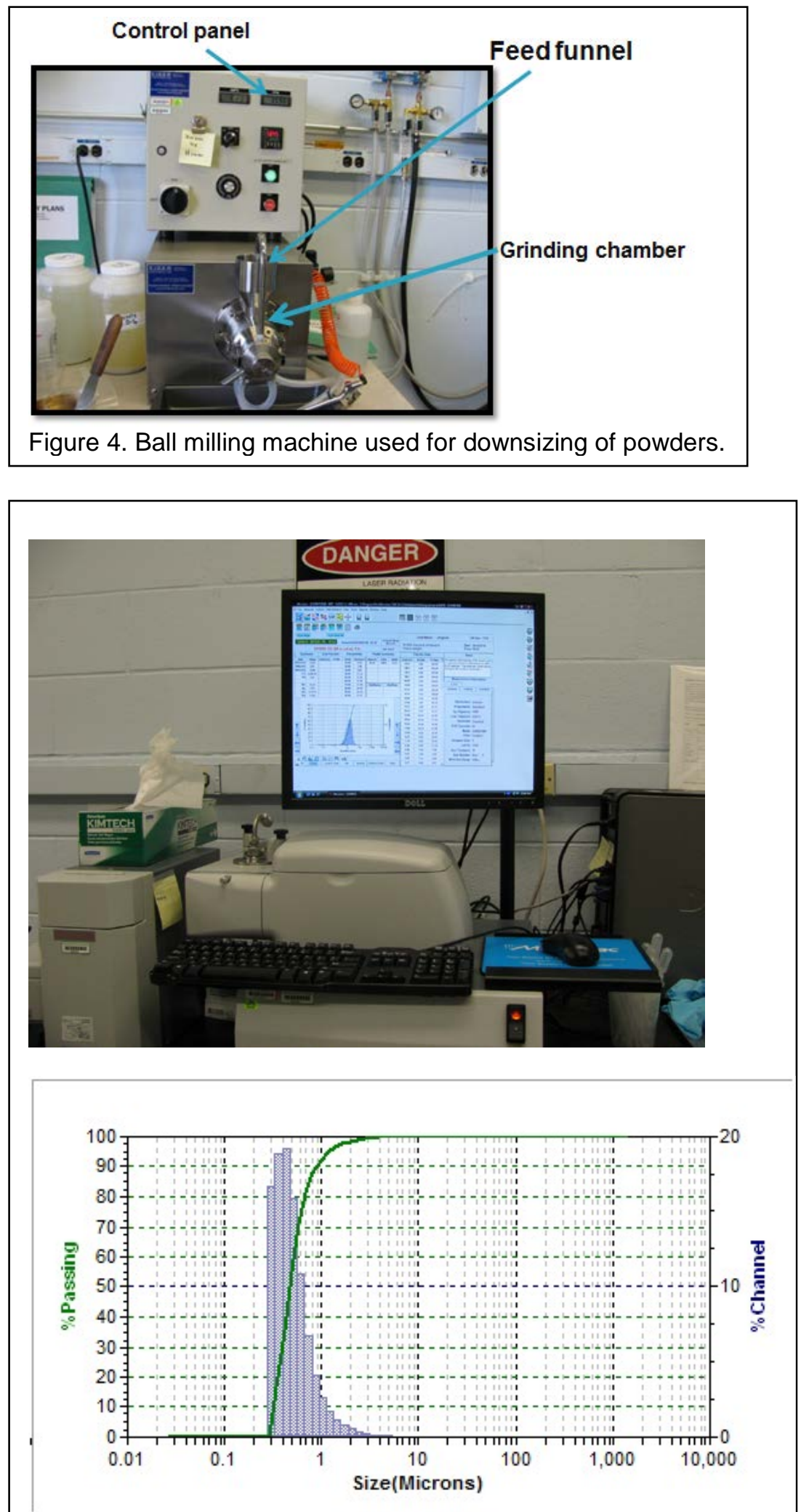

Figure 5. Particle size analyzer (top) and typical size distribution (bottom) of boric acid particles (at 5 wt.\% load) ball milled in PAO4 oil. 


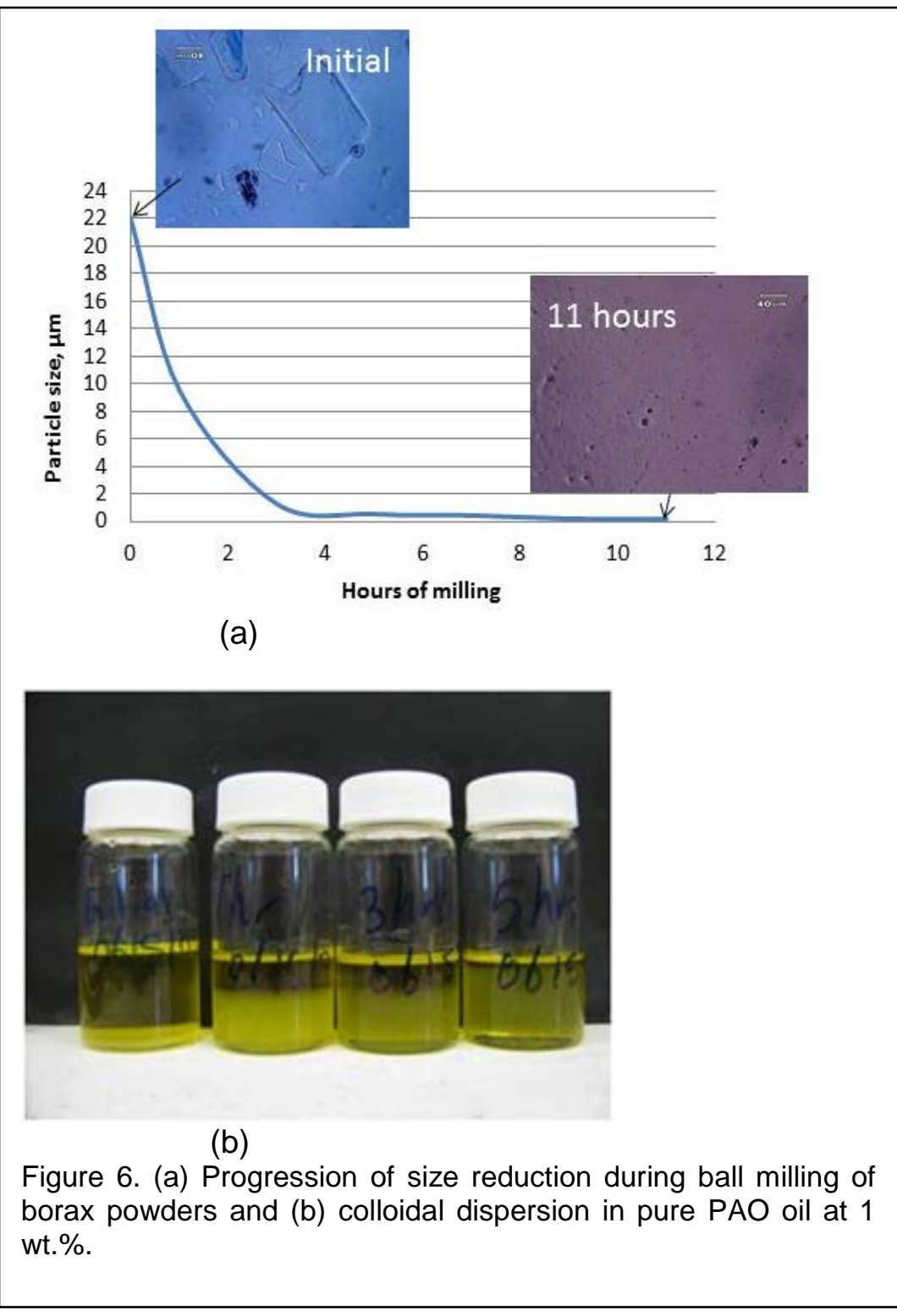


Because of a very high surface atom-to-bulk atom ratio, these fine particles can be mixed with various liquid lubricants (mineral, synthetic, and vegetable oils; greases; etc.) over a range of concentrations. Surface atoms in these particles should be chemically active mainly because of the multiple bonding possibilities (such as ionic, covalent, hydrogen, and van der Walls) available in them. Dispersion of these particles in oils with higher polarity (canola oil, polyol esters, etc.) appears to be much easier than non-polar hydrocarbon oils.

In an effort to perform our experiments in a more systematic manner, we used a particle size analyzer and a viscometer, which had proven to be very useful for our studies. The findings from these studies were useful in understanding what process parameters were most influential in attaining the optimum powder size, shape, and chemical/physical states in terms of achieving good colloidal dispersion. Accordingly, we produced a range of boron-based powders and mixed them with both the base and formulated oils at different concentrations. Extensive studies were directed toward surface chemical functionalization to achieve much longer shelf-lives in carrier oils. Overall, these systematic studies provided us with a scientific basis for acquiring a sound understanding of the relationship between various process parameters and the characteristics of the nanopowders in relation to the tribological performance in lubricating oils.

In order to realize very long stability/dispersibility of powders in carrier oils, we obtained and tested several surfactants (such as Sorbitan Trioleate, STO-MO) to determine their effectiveness in achieving very stable dispersion of boron-based powders. Some of the surfactants we tested indeed looked very promising as they kept the particles in colloidal dispersion for more than a month, while others did not work and could not prevent agglomeration and settlement. Particle size and concentration were also important factors; larger particles tended to separate faster (even when the most effective surfactant was used), while at higher concentrations, smaller particles stayed in colloidal dispersion (on top) but the larger ones still settled in the bottom. In our studies, we also found that adding surfactants prior to the milling operation not only greatly enhanced the dispersibility of particles but also expedited the size reduction of these particles, as shown in Fig. 7.

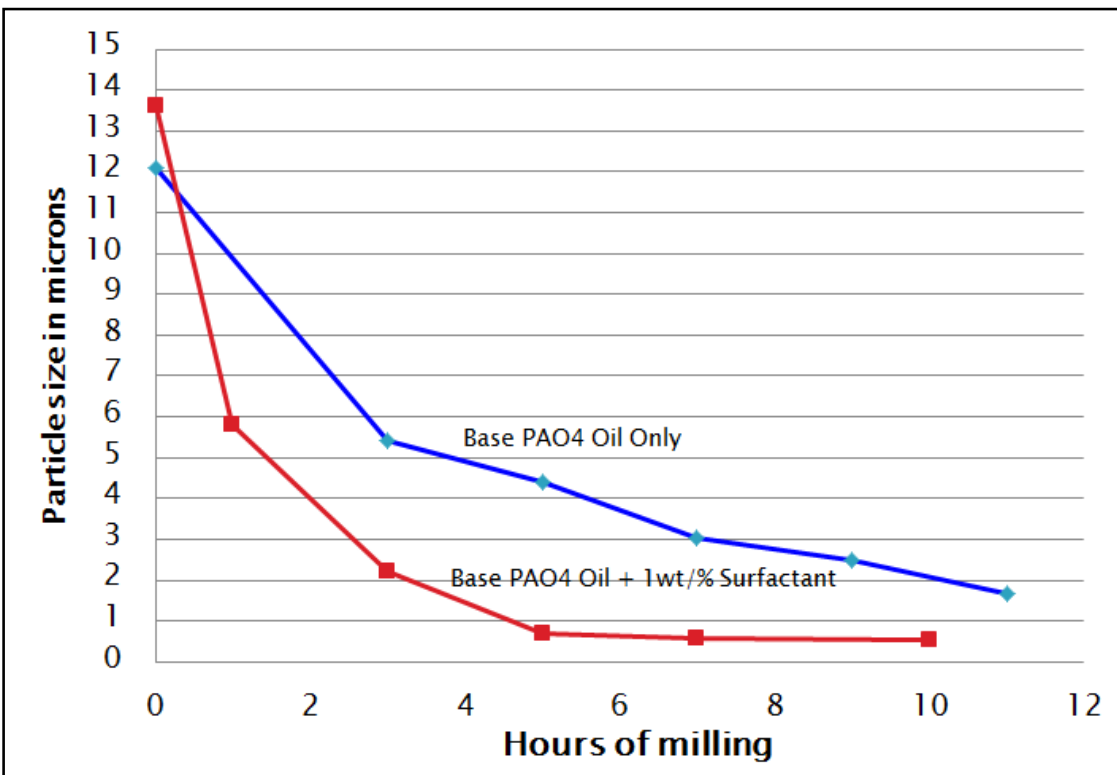

Figure 7. Effect of surfactant additive (SA) on size reduction of boric acid particles. 
Our studies also showed that, regardless of the chemical states of the particles, the type of surfactant used was very important. In fact, some of the surfactants had an adverse impact on size reduction and long-term dispersion. Figure 8a shows the typical size distribution of boron nitride particles as a function of milling time with three surfactant chemistries (designated 1, 2, and 3). The initial particle size of boron nitride powders was up to $3 \mu \mathrm{m}$. Without the use of any surfactant, boron nitride powders would agglomerate and turn into larger chunks, while surfactant 3 initially reduces the size to less than $1 \mu \mathrm{m}$ but then leads to larger size chunks, as shown in Fig. 8. The best results were obtained with Surfactants 1 and 2, which quickly reduced the boron nitride size to about 200 to $300 \mathrm{~nm}$, and the colloidal mixture prepared using these surfactants stayed very stable even after 3 months on the shelf, as shown in Fig. 8b.

We also determined that, if no surfactant is used, then the particles will separate or agglomerate upon exposure to high temperature, as shown in Fig. 9. As is obvious, the particles remain in perfect dispersion even at $100^{\circ} \mathrm{C}$ when surfactant was used during milling, while particles separate or agglomerate if surfactant is not used during milling.

Regardless of the ball milling operation, the structural morphology or crystalline nature of the boron powders had largely been preserved. As shown in Fig. 10, the electron diffraction pattern of the boron nitride particles was still the same as that of the original boron nitride material (even after a 40-hr ball milling operation). Furthermore, compared to other boron compounds, boron nitride was found to be much easier to downsize using our ball milling machine to below $100 \mathrm{~nm}$ and to keep in dispersion for a very long time. It also responded very well to some of the dispersion chemistries that we have tried.

In another study, we determined that some common vegetable oils (canola, soybean, rapeseed, and coconut oils) were also very compatible with the boron-based nanoparticles. In fact, when we tested them in base mineral or synthetic oils in the range of 1-5 wt.\%, we further accelerated the size reduction or milling process plus further enhanced the dispersibility. The possibility of using vegetable-based oils as dispersants sounded quite exciting since they are environmentally safe and rapidly degradable. In the case of boric acid particles, we could keep them in colloidal dispersion for more than 40 days in tests using a combination of canola and PAO base oils, while in the case of boron nitride and borax, such a mixture provided good dispersion up to 30 days. We feel that the highly polar nature of these vegetable oils was perhaps the reason for such a favorable outcome. These and other bio-based or -derived lubricants are being considered for a wide range of manufacturing operations due to their environmental safety. They are also being considered for use in engine oils (especially of earthmoving heavy-duty machinery operating in off-road areas); however, their relatively poor oxidation resistance might be a problem in such applications. Blending them with engine oils at a concentration range between 1 and 5 wt.\% may be acceptable. 


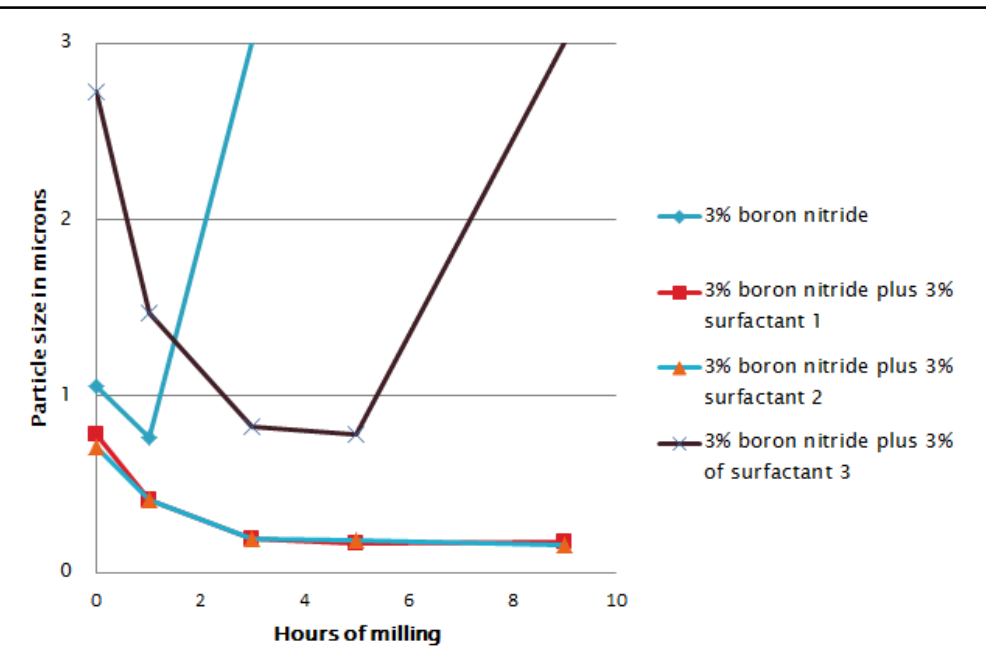

(a)

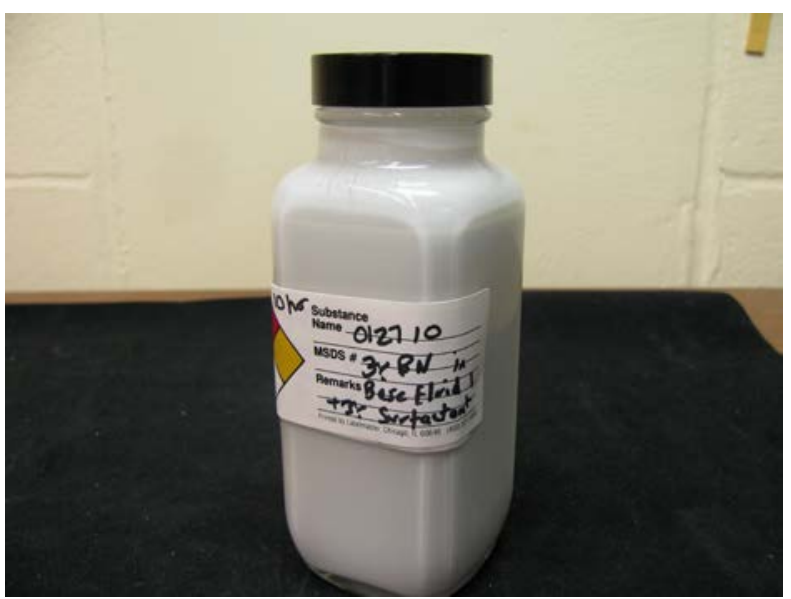

(b)

Figure 8. (a) Effect of surfactant type on size reduction of boron nitride during ball milling and (b) photo of boron nitride colloid prepared using surfactant 1 after 3 months on the shelf. 


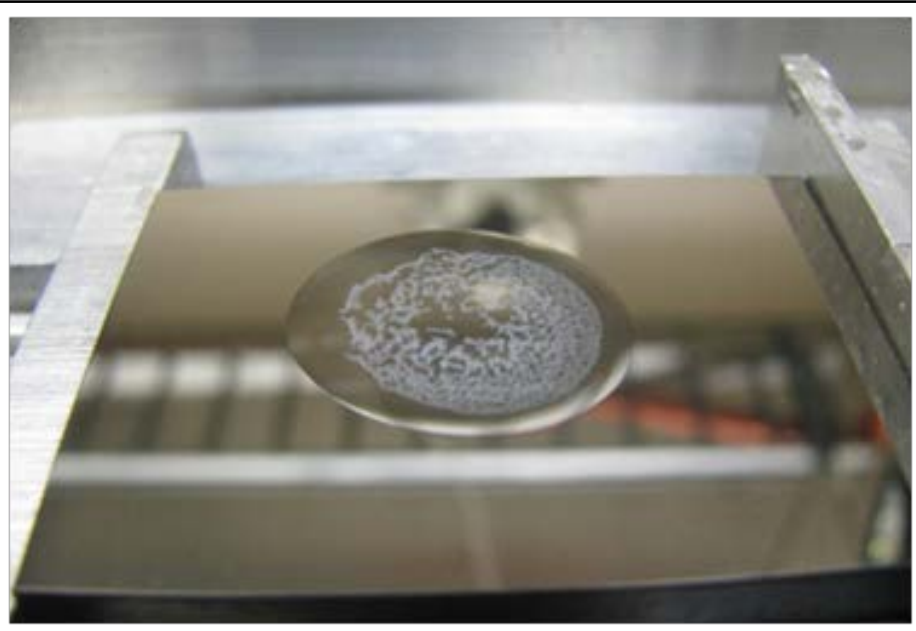

(a)

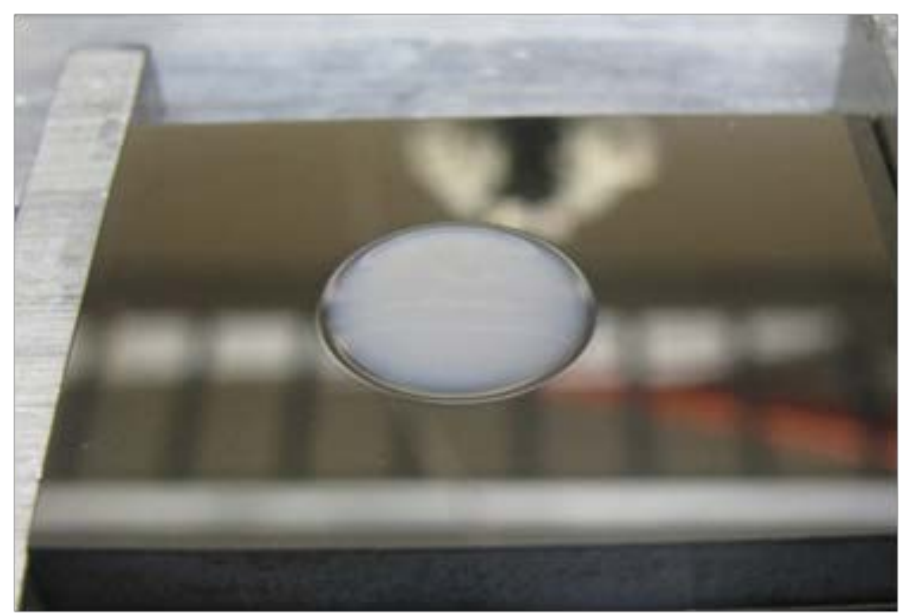

(b)

Fig. 9. Photograph of (a) 5 wt.\% boric acid containing PAO4 alone and (b) 5 wt.\% boric acid with 1 wt.\% sorbitan trioleate (STO-MO) surfactant in PAO4 at $100{ }^{\circ} \mathrm{C}$. 


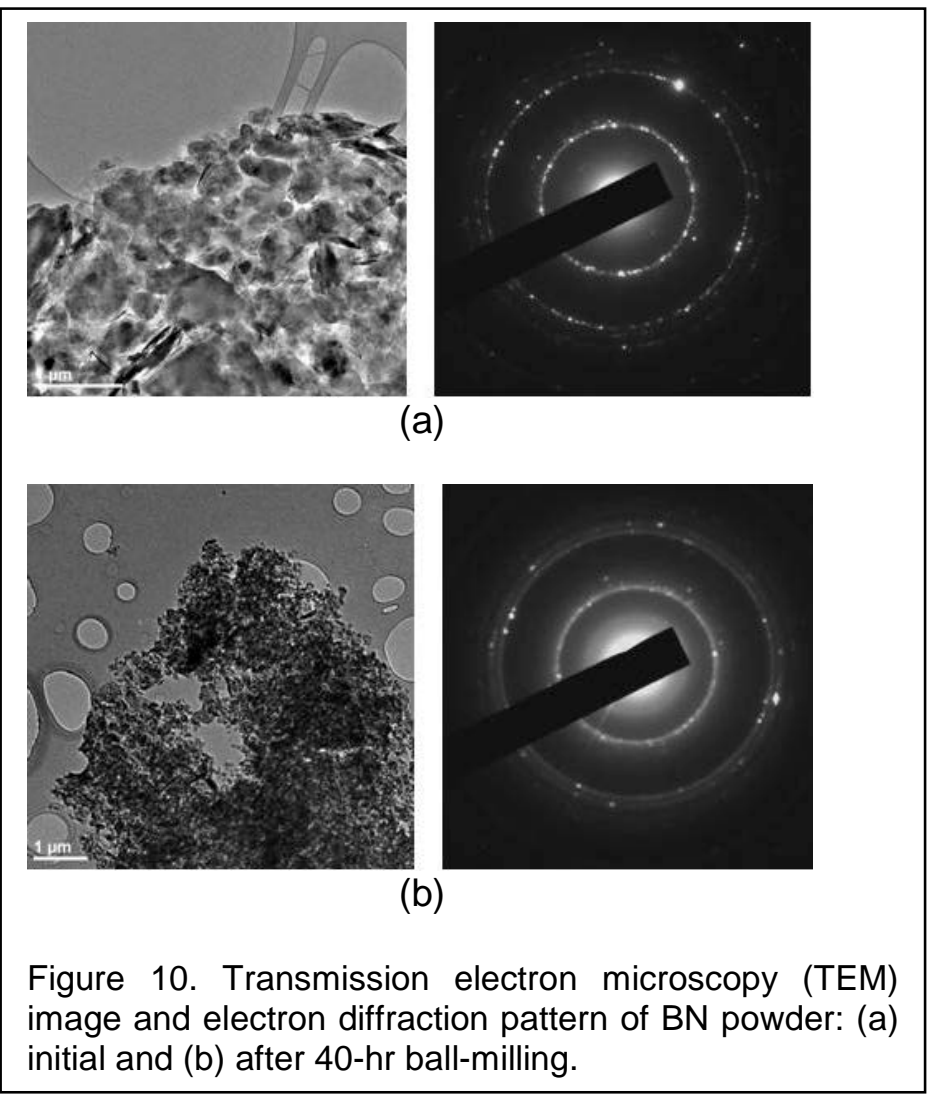

Based on the favorable experience on vegetable oil studies, we searched and found numerous bio-derived surfactants (canola, coconut oil, rapeseed oil, etc.) and tested them for effectiveness in dispersing boron-based particles in oils. Some of them worked very effectively in terms of keeping particles in colloidal dispersion for a long time. In particular, boric acid and borax nanoparticles responded well to modified canola and coconut oil-based surfactants when added prior to ball milling even at very low concentrations, such as $0.5 \%$. In summary, out of these studies we found that those vegetable oils or bio-derived surfactants with a stronger polar nature seem to work extremely well with boron-based particles. Specifically, the highly polar nature of these oils provided a high degree of dispersibility and also resulted in very significant reductions in friction and wear coefficients of sliding steel surfaces lubricated by these oils.

Out of these systematic studies, we discovered that boron nitride and boric acid powders are highly compatible with canola, soybean, coconut, and rapeseed oils. Owing to their highly polar natures, these oils mix quite well with the powders even at very high concentrations without any settlement. When these concentrates are mixed with fully formulated engine oils, the result was a clear fluid, suggesting that the boric acid had become an integral part of these formulated oils. This finding indicates that no additional dispersion agent is needed to blend boric acid with the formulated engine oil. Figure 11 shows a fully formulated oil blended with $5 \%$ of milled boric acid in canola oil, modified canola oil, and soybean oil. As evident in the figure, they all produced a clear liquid with no evidence of any powder separation or settlement in the bottom.

It is important to note that vegetable or bio-derived lubrication additives and other products are gaining increased interest due to their minimal environmental impact and renewable nature. In particular, moving mechanical systems used in all types of machining and manufacturing 
applications can benefit from such additives due to their biodegradability and other environmental/health benefits. There is also a growing interest in these oils for automotive and food-processing applications. All of the vegetable-based surfactants we worked with were environmentally safe, cheap, and easy to handle.

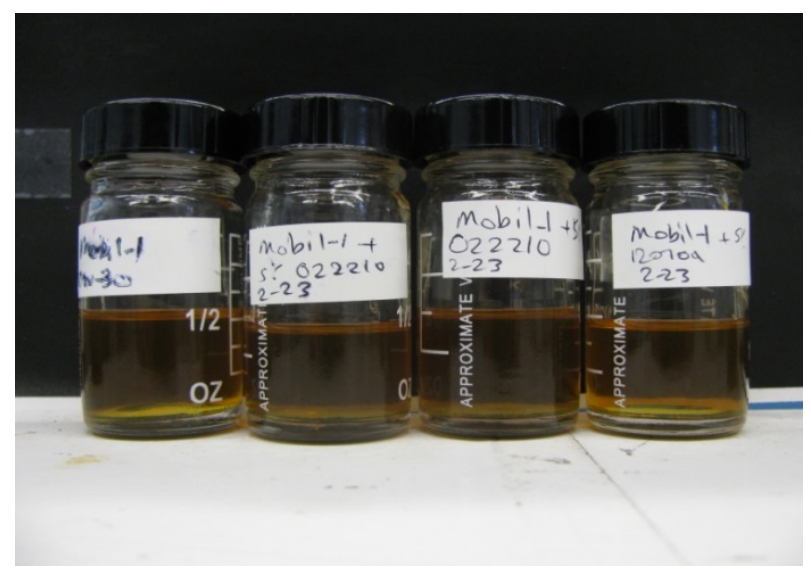

Figure 11. Blending of a fully formulated synthetic oil with $5 \%$ of milled boric acid in canola oil, modified canola oil, and soybean oil. The result was a clear product that was very stable for a long period of time.

As part of powder manufacturing and surfactant studies, we also explored the effects of several other parameters, including bead size, bead load, bead tumbling speed, and ball-milling temperature. Among the many parameters investigated, bead size showed the greatest influence. Specifically, when we used different ball sizes in our ball milling machine to determine the effect of milling time and ball diameter on particle size, smaller beads or balls (i.e., $0.3 \mathrm{~mm}$ in diameter) resulted in much finer particle sizes and much better dispersion in base synthetic oils than the larger (1-mm diameter) balls. Overall, using our in-house ball milling machine, we successfully manufactured many types of powder (boric acid, borax, and boron nitride) and blended them with a range of base, vegetable, and fully formulated engine oils.

Attempts to manufacture larger-scale nanopowders by our industrial partners were also successful and demonstrated the potential scaleability of the process if and when there is a need for large-scale nanopowder production. Oil blends prepared using their nanopowders were tested for friction and wear performance, and performance improvements were similar to those of the smaller-scale ball milling operations performed in-house.

\subsection{Friction and Wear Studies of Boron-based Additives}

We performed numerous tribological tests using boric acid, boron nitride, and borax powders manufactured internally or supplied by our partners. These tests were performed with a variety of bench-top tribo-test systems such as pin-on-disc, block-on-ring, ring-on-liner, and reciprocating configurations. They were designed to elucidate the effects of powder size, concentration, temperature, and thermal cycling on the friction, wear, and scuffing properties of baseline and blended lubricants. Of particular interest was the optimum particle size and concentration needed to achieve best overall performance in terms of friction, wear, and scuffing. In our studies, a wide range of advanced surface analytical techniques such as 3-D optical interferometry, scanning and transmission electron microscopy (SEM and TEM), x-ray 
diffraction (XRD), x-ray photo-electron spectroscopy (XPS), electron Auger spectroscopy (AES), and time-of-flight (TOF) secondary ion mass spectrometry (SIMS) have all been used during the course of our project to obtain critical information on wear volume, scuffing limits, tribochemistry, and fundamental mechanisms associated with the formation of low-friction, low-wear boundary films. These characterization studies proved to be effective in terms of understanding the lubrication mechanisms of boron-containing oils under severe tribological test conditions.

Initial screening studies were run with base oils and a number of boron-based powders (boric acid, boron nitride, borax, boron oxide, etc.) at different particle size and concentrations and under a wide range of test conditions with and without the use of a surfactant. Figure 12 shows the effect of boric acid powder concentration on the friction and wear of sliding steel surfaces. Pure PAO without any additive resulted in very high friction and wear in these tests; by contrast, adding 1 wt.\% boric acid into it without any surfactant did not make much difference in friction but wear was reduced slightly. With the use of surfactant and $5 \mathrm{wt} \%$ boric acid particles together, the friction coefficient declined to 0.07 , which is a great improvement over that of a fully formulated engine oil, as shown in Fig. 12a. Overall, combination of 5 wt.\% boric acid and 1 wt. $\%$ surfactant reduced the friction coefficient by $58 \%$ and $42 \%$ as compared to the base PAO and fully formulated oils, respectively. Regarding the wear, $1 \mathrm{wt} \%$ and $5 \mathrm{wt} \%$ surfactantfunctionalized boric acid containing PAO afforded the lowest wear, even lower than that for fully formulated engine oil. 


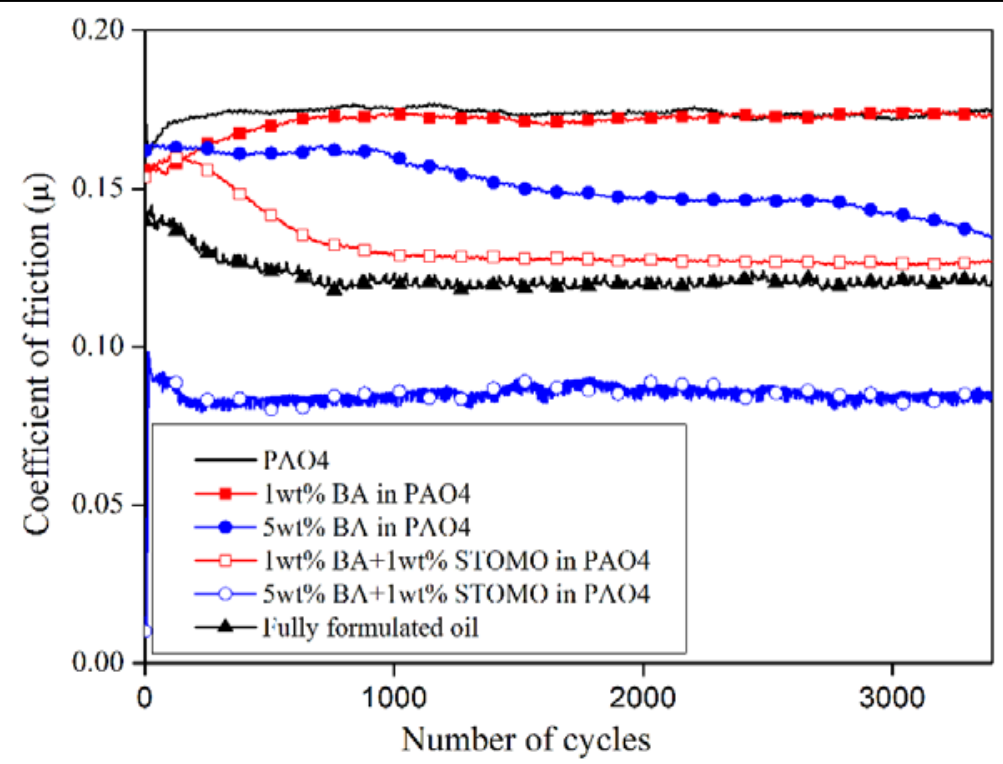

(a)

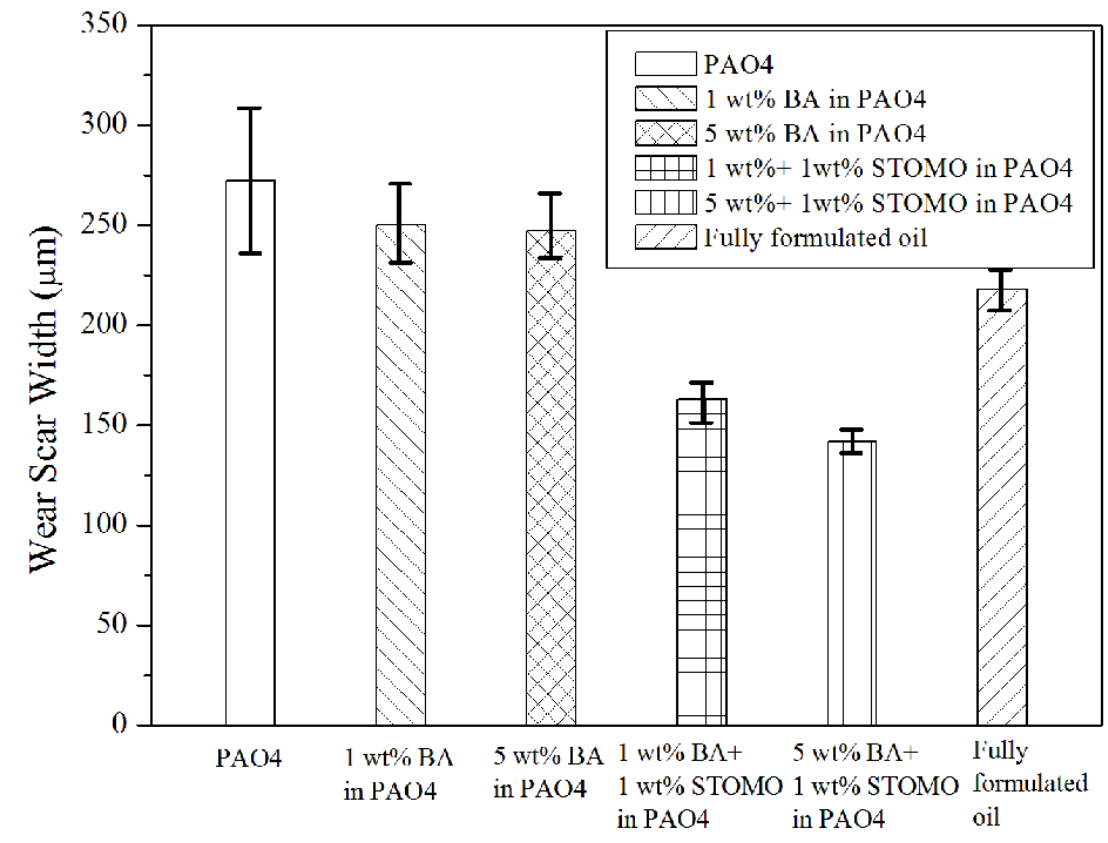

(b)

Figure 12. (a) Friction coefficient for cylinder and flat specimens versus number of cycles and (b) wear after testing under different lubricated conditions at an applied load of $325 \mathrm{~N}$.

The sliding surface after testing in pure PAO looked rough and highly deformed (see Fig. 13a), while that produced in surfactant-functionalized PAO was smooth, as shown in Fig. 13b. For the case of 5 wt.\% boric acid with surfactant, the wear scar width was reduced about $47.8 \%$ compared to the base-oil-only case. The microscopic image of the worn surface in pure PAO (Fig. 13a) shows some signs of abrasive wear and possible plastic deformation, but no such features were observed in the corresponding image of the PAO that contained boric acid 
particles (see Fig. 13b). We believe that the much higher friction and wear in the pure PAO case was most likely due to the absence of a boundary film and progression of the abrasive wear resulting in an increasingly rougher surface finish and, hence, higher friction between the sliding surfaces. The sliding surfaces of test pairs for both 1 wt. $\%$ and 5 wt. $\%$ boric acid containing oil were smoother than those formed in pure PAO4 (see Fig. 13). With 5 wt.\% boric acid plus surfactant, the worn surface looked smooth, and the lower friction and wear in Fig. 12 may have been due to the formation of a smooth, slick, and protective boundary film that was rich in boric acid and provided good protection against wear.

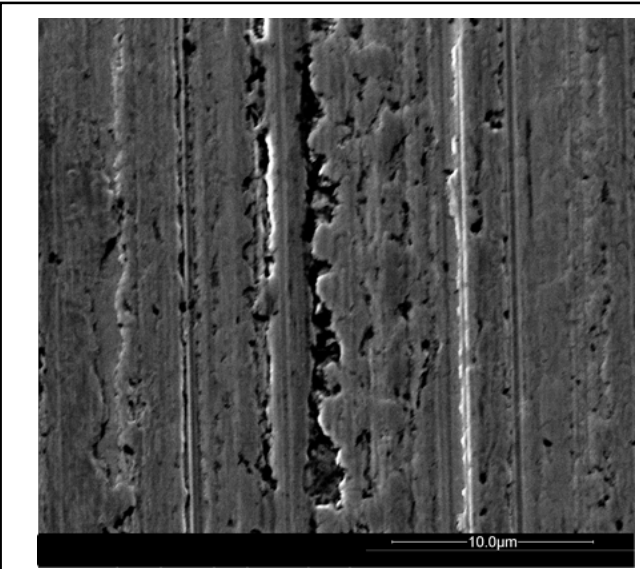

(a)

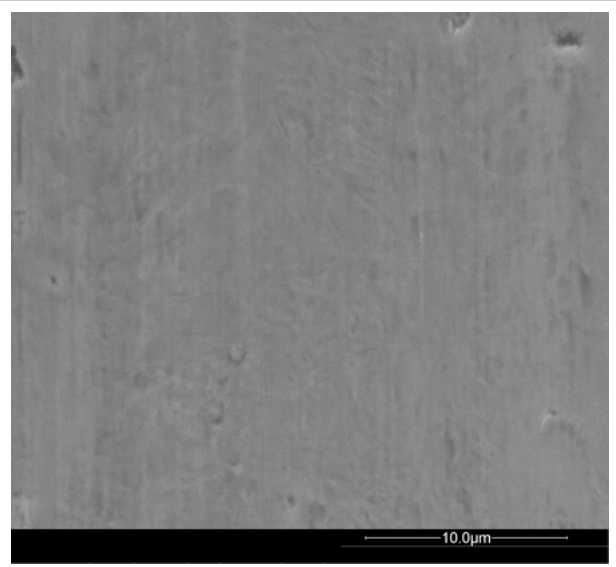

(b)

Figure 13. Field emission SEM images of worn surfaces after test in (a) pure PAO and (b) surfactant-functionalized boric acid containing PAO.

The wear tracks on the flat test samples were characterized by XPS to reveal the extent of tribochemical interactions during tests with different lubricants: pure PAO4, PAO4 + boric acid, and PAO4 + boric acid + STO-MO. The elemental compositions of the tribofilms formed on the wear track are given in Table 1 . These results were mainly from the analysis of the top $5 \mathrm{~nm}$ (no etching) of the tribofilm; therefore, we performed depth profiling with AES to determine the elements present beneath the top surface layer.

Figure 14 shows the general XPS spectra of the tribofilms formed on the sliding surfaces during tests in the different lubricants. It was clearly observed that only boric acid and boric acid + STO-MO resulted in boron-rich boundary films, as the general spectra revealed clear boron peaks. The lubricant with boric acid + STO-MO formed a more carbon-rich tribofilm in comparison with other tested lubricants. Thus, the carbon-rich sorbitan trioleate (shown in Fig. 14) may have interacted synergistically with boric acid and formed a lubricious protective film, as presented in Fig. 13, and hence attained very good tribological performance. The highly polar nature of the STO-MO was thought to play a significant role in the excellent dispersion of the nanoparticles and strong interaction of these particles with sliding surfaces. Again, the tribological performance of this particular colloidal lubricant was much superior to the fully formulated engine oils that are in use today. This was a very important discovery of this project. 


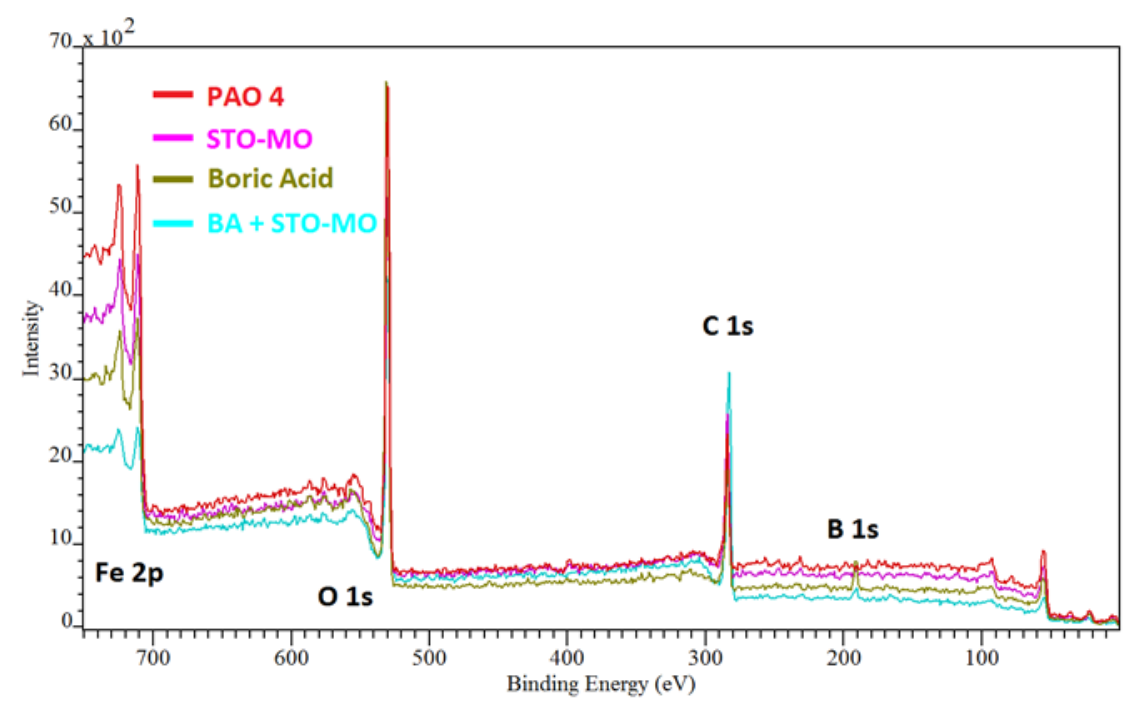

Figure 14: General XPS spectra of tribofilms (i.e., protective boundary film) formed on various surfaces during tests in pure PAO4, PAO4 + STO-MO, PAO4 + boric acid, and PAO4 + boric acid + STO-MO.

Table 1. XPS quantification (in atomic \%) of tribofilms formed on flat samples

\begin{tabular}{|c|c|c|c|c|}
\hline & PAO4 & $\begin{array}{c}\text { PAO4 + } \\
\text { BA }\end{array}$ & $\begin{array}{c}\text { PAO4 + } \\
\text { STO-MO }\end{array}$ & $\begin{array}{c}\text { PAO4 + BA + } \\
\text { STO-MO }\end{array}$ \\
\hline C 1s & 39 & 35 & 50 & 45 \\
\hline O 1s & 41 & 44 & 35 & 25 \\
\hline Fe 2p & 20 & 11 & 15 & 5 \\
\hline B 1s & - & 10 & - & 25 \\
\hline
\end{tabular}

As expected, PAO4 interaction on the steel surface resulted in a film that was rich in oxygen and carbon, confirming that the rubbing surfaces were highly oxidized (Table 1). However, with the use of $5 \mathrm{wt} . \%$ boric acid alone in PAO4, the tribofilm showed a significant amount of boron. For comparison, we included results from a surface that was tested in surfactant + PAO4 lubricant. In this study, combination of boric acid and STOMO in PAO4 lubricant gave excellent friction and wear performance (as already shown in Fig. 12), and the XPS investigation of the tribofilm formed on sliding steel surfaces clearly revealed a very high concentration of boron along with carbon, oxygen and iron compounds. Detailed investigations were conducted to identify the chemical species of the tribofilms. PAO4 alone produced a wear scar composed of iron oxides and carbon/oxygen species. The surfactant-based PAO4 had a significant influence on the chemistry of the wear scar as it was rich in carbon species from the surfactant. The lubricants with boric acid alone and boric acid + surfactant led to the formation of boron-rich tribofilms; but the overall chemistry of the film was considerably different. Boric acid alone in PAO4 led to formation of a tribofilm with typical carbon and oxygen species but significant presence of boron oxides (see Fig. 15a). However, boric acid with surfactant in PAO4 formed a tribofilm with some carbon species (presumably from the surfactant); moreover, there was a high presence of boron, mainly in the form of boron oxides and decomposed boric acid. We believe that the presence of decomposed boric acid (Fig. 15b) was important for mitigating wear damage and reducing friction. 


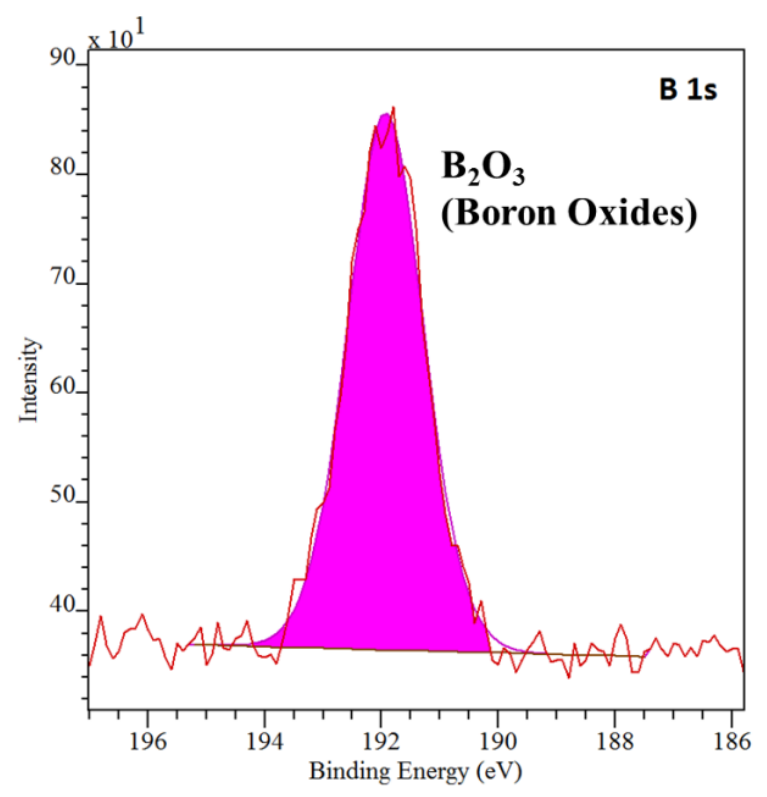

(a)

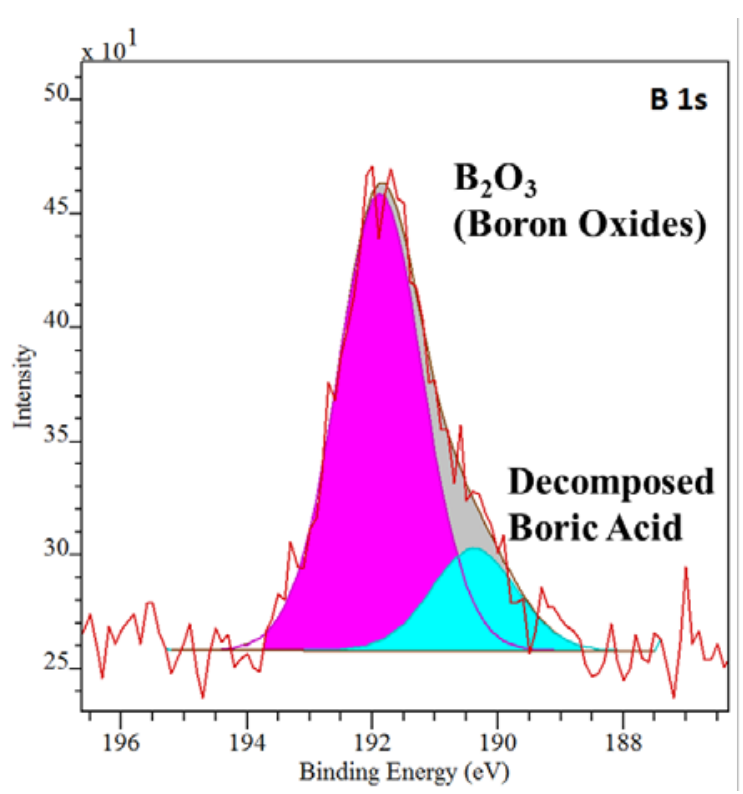

(b)

Figure 15. XPS peaks for tribofilm compounds resulting from the testing of (a) 5 wt.\% boric acid in PAO4 and (b) 5 wt.\% boric acid with surfactant in PAO4 on steel surfaces.

Although XPS studies had confirmed that PAO4 with boric acid alone and surfactant + boric acid could form a tribofilm that was very rich in boron (Table 1 and Fig. 15), they only provided chemical information for the top $5 \mathrm{~nm}$ of the surface. Hence, we also investigated the chemical nature of the whole tribofilm using AES. Figure 16 provides the AES elemental depth profiles of the tribolayers produced by boric acid alone and surfactant + boric acid. As is obvious, the tribofilm formed from surfactant + boric acid had very high boron concentration near the top and well into the subsurface, in contrast to much lower boron for the case of boric acid alone. Interestingly, the oxygen concentration was higher in the case of boric acid alone, but it decreased steadily with increasing depth in the case of boric acid + surfactant. Overall, the XPS and AES analyses confirmed that PAO4 lubricant containing boric acid + surfactant provided a synergistic effect and resulted in the formation of a more effective tribofilm that helped to minimize friction and wear losses. Moreover, the boron-rich tribofilm was much thicker and thus more durable and protective. 


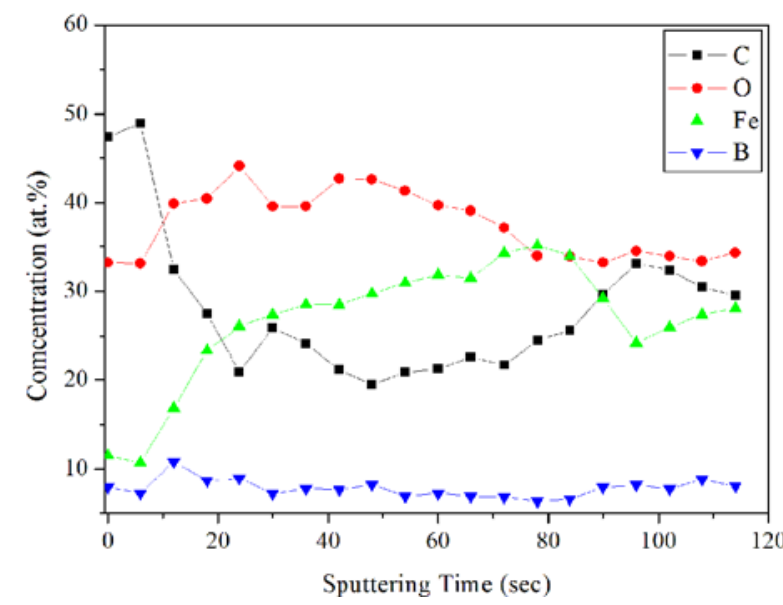

(a)

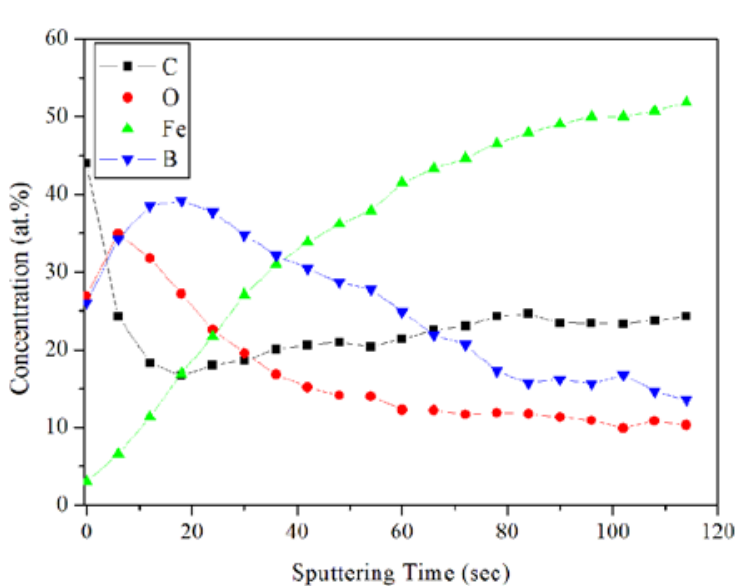

(b)

Figure 16. AES profile diagram of (a) 5 wt.\% boric acid in PAO4 and (b) 5 wt.\% boric acid with 1 wt.\% surfactant in PAO4 on steel surfaces.

Based on the results from the base oil studies, we confirmed the presence of robust tribochemical interaction between boric acid particles and sliding steel surfaces, especially in the presence of a surfactant. Without the surfactant, particles tend to agglomerate and turn into larger clusters. We believe that this effect might have induced a weak and inhomogeneous interaction with the sliding surfaces, especially at high temperatures (see Fig. 9). This interaction resulted in the formation of a weak boundary film, which, in turn, resulted in higher friction and wear losses, as shown in Fig. 12. By contrast, surfactant was able to minimize the agglomeration and thus provide good dispersion and availability of particles for tribochemical interactions, even at high temperature. This behavior resulted in a low-shear tribofilm formation on rubbing surfaces and thus helped reduce friction and wear. This low-shear boundary film also ensured a smooth surface finish (see Fig. 13), which may have further helped in friction reduction.

In order to further confirm the beneficial impact of boric acid on friction and wear (especially under severe boundary conditions), we designed a special test protocol in which the speed is first decreased from a reasonably high value $(0.08 \mathrm{~m} / \mathrm{s})$ to a lower value $(0.018 \mathrm{~m} / \mathrm{s})$ to near zero, then back to the high value. Figure 17 shows the results of these tests with pure PAO4 and PAO4 + boric acid particles. As can be seen, base PAO4 oil without any particulate showed friction coefficients of 0.1 to 0.16 at the higher sliding velocities but at the lowest sliding velocity, the friction coefficient jumped to values as high as 0.32 . These results confirm that base oils do not provide good lubrication and wear properties when sliding surfaces are in direct contact and under severe pressures. With the inclusion of boric acid as additive, the friction coefficient was reduced across the speed range tested, as was the amount of wear damage on the sliding ball side (400 $\mu \mathrm{m}$ for pure PAO4 vs. $177 \mu \mathrm{m}$ for PAO4 + boric acid additive). Also, the amount of friction at the slowest sliding regime and under the severe boundary condition was about $75 \%$ lower, presumably due to the formation of a highly protective boron-rich boundary film as discussed earlier. 


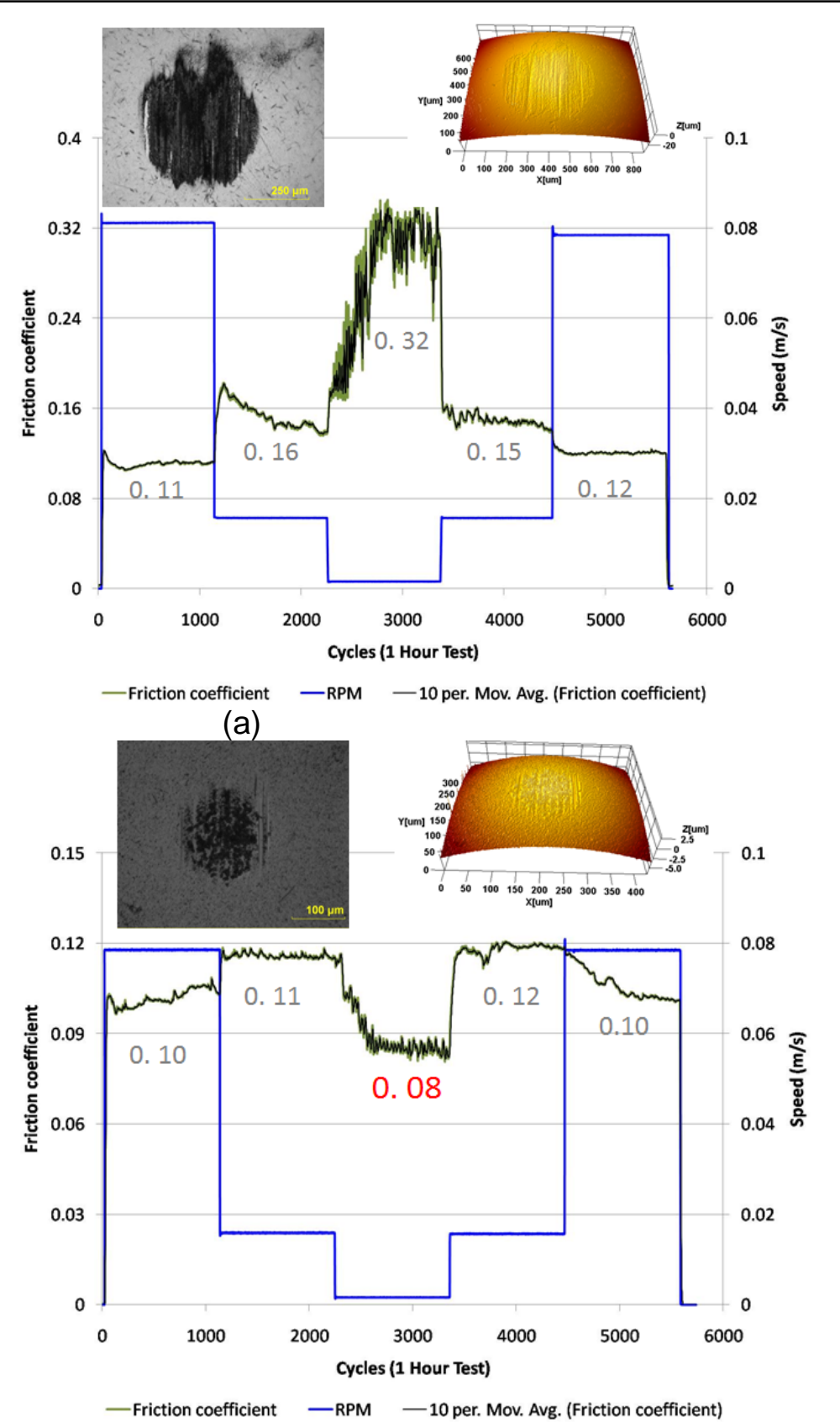

(b)

Figure 17. Friction and wear behavior of PAO4 oil (a) without and (b) with boric acid additive.

Base oil studies with hexagonal boron nitride powders have also resulted in a beneficial effect from the high lubricity of this particulate additive. During these initial tests, as in the case of boric acid, when boron nitride was milled in the presence of a surfactant, the friction and wear were reduced even further, while without surfactant, the milled boron nitride agglomerated and resulted in higher friction and wear losses. Figure 18 shows the frictional behavior of base PAO4 oil with and without boron nitride powders and the surfactant. As is clear, despite the very severe test conditions and at $0.25 \mathrm{wt} \%$ boron nitride additive, there was a noticeable reduction 
in friction and wear of sliding surfaces. At a higher boron nitride concentration of 1 wt.\%, the improvement in friction and wear remained marginal; it looked that $0.25 \mathrm{wt} \%$ boron nitride in carrier PAO was sufficient to trigger the beneficial effect.

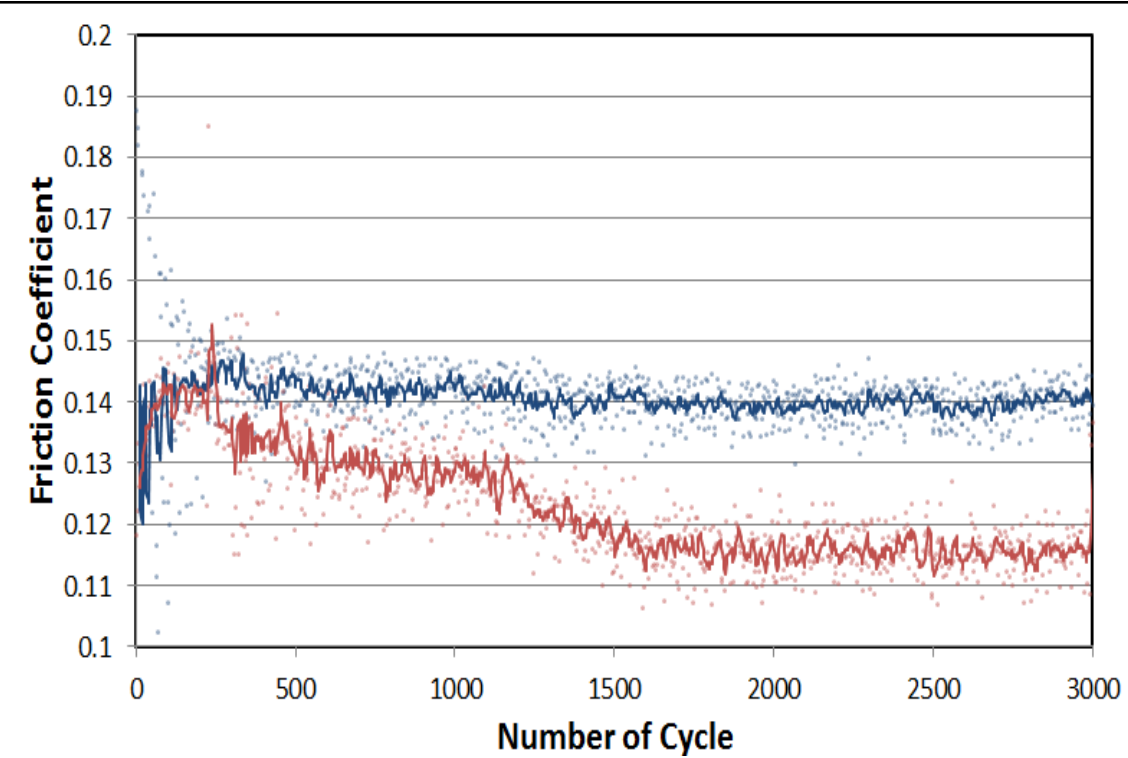

Figure 18. Friction and wear behavior of PAO4 oil with (red curve) and without (blue curve) boron nitride additive.

Cross-sectional focused ion beam analysis by transmission electron microscopy (FIB-TEM) was performed on a few samples that had been tested in PAO4 + boron nitride to determine if any type of boundary film had formed on their sliding surfaces. As shown in Fig. 19a, a tribofilm had formed right on top of the sliding steel substrate, and its thickness ranged from about 100 to 250 $\mathrm{nm}$. Electron diffraction and XPS studies further confirmed that the tribolayer was essentially made up of iron oxide and boron nitride, as shown in Figs. 19b and 19c.

Fine boron nitride particles were also incorporated into fully formulated engine oils and tested for their effectiveness in friction and wear. The friction results were very comparable under a 1 GPa contact pressure at $80^{\circ} \mathrm{C}$ temperature, i.e., around 0.11 for fully formulated engine oil and 0.1 for 1 wt.\% boron nitride-containing oil. However, the wear scar width on the cylindrical pin side was reduced substantially, i.e., $210 \mu \mathrm{m}$ vs. $170 \mu \mathrm{m}$ after a 15-hour test. The general XPS survey spectrum of the tested surfaces revealed that the boundary film consisted of all the major anti-friction and wear species (Zn, Mo, P, S, etc.) of fully formulated oil plus the boron from boron nitride. Some of the boron seems to have been oxidized during the rubbing action, while some remained as boron nitride. 


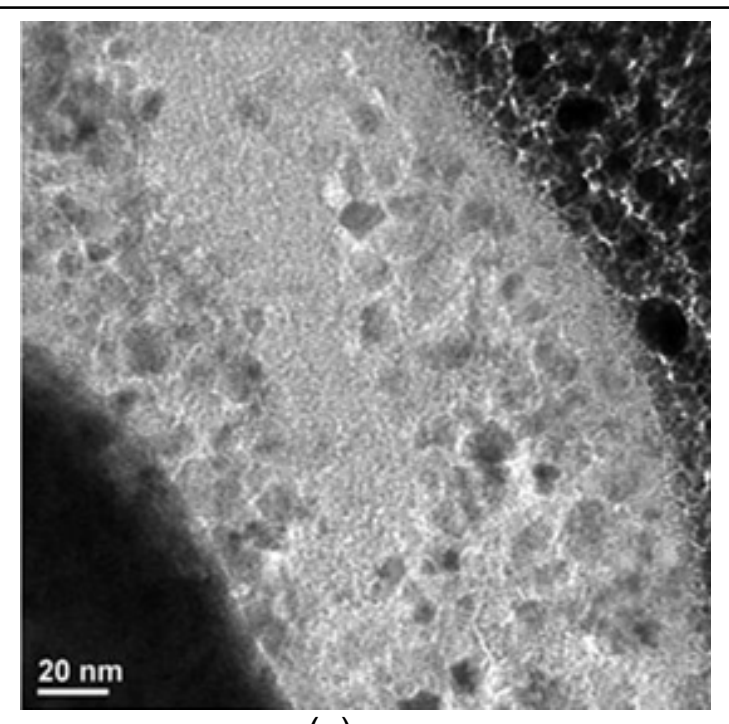

(a)

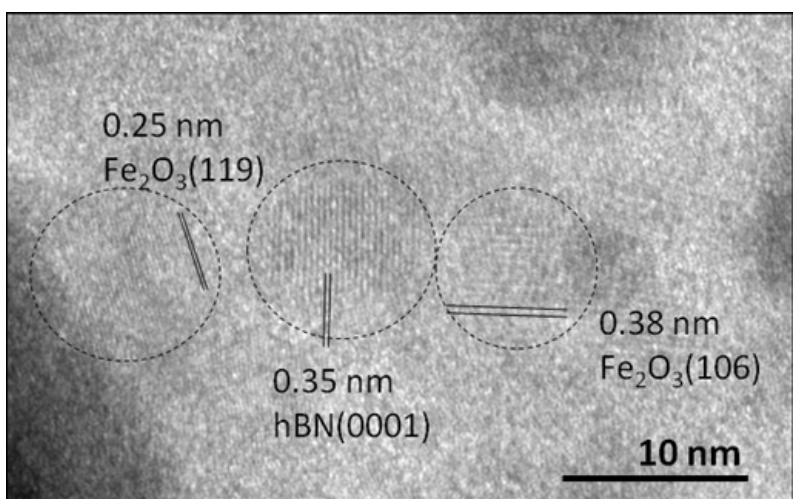

(b)

\section{XPS Analysis}
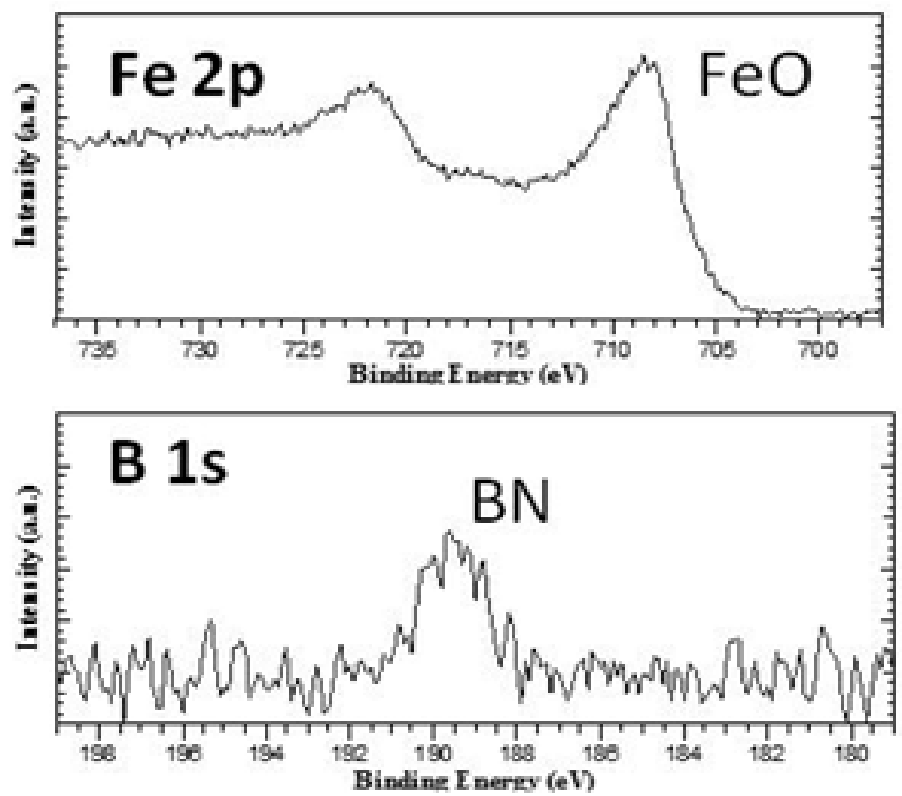

(c)

Figure 19. (a) Coarse and (b) high-resolution TEM images, and (c) XPS spectra taken from the tribofilm formed in tests of PAO4 + boron nitride.

High-resolution XPS combined with TOF-SIMS of friction- and wear-tested surfaces helped us greatly in the elucidation of the chemical nature of the boundary films formed on these surfaces. In general, these analyses confirmed that the boundary film formed on these surfaces during sliding was fairly thick (more than 50-nm thick), and primarily consisted of large amounts of oxide-based boron compounds that appeared to have reacted with Fe from the steel samples and $\mathrm{Zn}, \mathrm{S}$, and $\mathrm{P}$ from the additive packages. Structurally, the boundary film was amorphous in 
the case of boric acid but somewhat crystalline in the case of boron nitride.

The TOF-SIMS chemical analysis of the same film (see Fig. 20) revealed that it primarily consisted of boron and some organic compounds (containing zinc, phosphorus, and sulfur). The elements other than boron may have come from the additive package of the carrier oil (in this case, a fully formulated engine oil). The significance of this observation is that our nanolubricants are compatible with the current additive packages and capable of further enhancing their friction- and wear-reducing capacity. The protective boundary film formed on the sliding surface was one of the main reasons for their excellent resistance to wear and scuffing. Due to the layered nature of the nanosize boron nitride and boric acid powders, they are also low shear materials and, hence, afford low friction during sliding.

Using a steel block-on-ring test machine, we assessed the scuffing performance of the base PAO containing different levels of conventional additives and boric acid (BA). Specifically, in addition to base oil, we evaluated the friction, wear, and scuffing behaviors of base oil + full passenger car package, base oil + antioxidant, base oil + full passenger car package without friction modifier, and base oil + full passenger car package without friction modifier and dispersant. Table 2 summarizes all the results obtained from this series of tests. As is clear, the steel block-and-ring samples could scuff at loads as low as $230 \mathrm{~N}$ when a PAO oil was used. Addition of the antioxidant additive had no significant effect on the scuffing load. With the full passenger additive package (synthetic 5W30), the scuffing load increased to 1200-1250 N. These baseline tests clearly stressed the importance of oil additives in tribological performance.

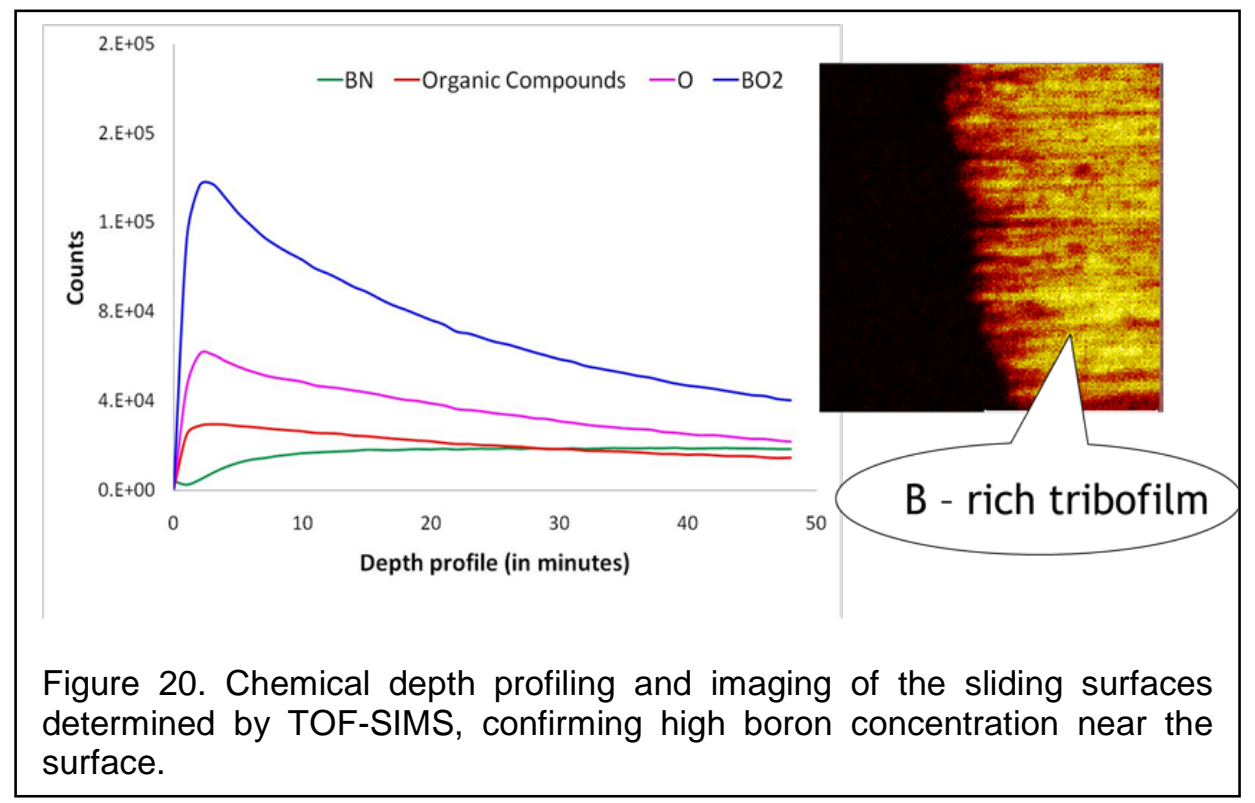

Compared to base and fully formulated engine oils, the BA-containing oil blends were in most cases very effective in reducing friction and increasing resistance to wear and scuffing in these test series as well. In particular, the scuffing limit for blends that contained 0.25 to $0.5 \mathrm{wt} \%$ boric acid powders in base oil + antioxidant improved by a factor 2 (i.e., 230-300 N vs. 560 to $660 \mathrm{~N}$ ). In the case of the full passenger car package without friction modifiers, BA-containing oils surpassed the scuffing limit of the commercial fully formulated synthetic oils by $350 \mathrm{~N}$. At 1 wt.\% load, the scuffing limit decreased, thus confirming that the optimum range was 0.25 to 0.5 wt.\%. The scuffing load of commercial synthetic oil in this case was about $1250 \mathrm{~N}$, but the 
nanoparticle boric acid containing the new oil blend was as high as $1600 \mathrm{~N}$. Such impressive performance persisted even in the total absence of a friction modifier in the carrier oils. Note that the level of friction coefficients provided by boric acid additives is comparable to that of fully formulated oils with friction modifiers; however, friction modifiers used in current oils are expensive and a source of SAPS in engines. Despite the lack of any friction modifiers in this oil blend, the friction coefficient of this BA-containing oil blend was comparable to that of the fully formulated synthetic oils.

Table 2. Scuffing and friction performance of different types of oils with and without boron additive.

\begin{tabular}{|c|c|c|}
\hline Lubricant & Scuffing load (N) & $\begin{array}{l}\text { Friction } \\
\text { Coefficient }\end{array}$ \\
\hline $\mathrm{PAO}-4$ & $230-300$ & 0.10 \\
\hline Full synthetic 5W30 & $1200-1250$ & 0.11 \\
\hline $\begin{aligned} \text { PAO + antioxidant only } & \\
& +0.25 \% \mathrm{BA} \\
& +0.5 \% \mathrm{BA} \\
& +1 \% \mathrm{BA}\end{aligned}$ & $\begin{array}{l}220-280 \\
560-660 \\
520-550 \\
520-660\end{array}$ & $\begin{array}{l}0.09-0.10 \\
0.11-0.12 \\
0.105-0.12 \\
0.10-0.11\end{array}$ \\
\hline $\begin{array}{l}\text { Full passenger car package + friction } \\
\text { modifier only } \\
\qquad \begin{array}{l}+0.25 \% \text { BA }(\mathrm{T} 504229-2) \\
\quad+0.5 \% \text { BA }(\mathrm{T} 504229-5) \\
\quad+1 \% \text { BA }(\mathrm{T} 504229-8)\end{array}\end{array}$ & $\begin{array}{l}1125-1150 \\
1500-1600 \\
1500-1600 \\
950-1100\end{array}$ & $\begin{array}{l}0.11-0.12 \\
0.10-0.12 \\
0.10-0.12 \\
0.10-0.12\end{array}$ \\
\hline
\end{tabular}

Of the four BA-containing oil blends that we received from our lubricant partner $u$, one looked extremely promising. These blends were in the forms of synthetic base oil mixed with different size nanoboric acid powders, from $50 \mathrm{~nm}$ to $500 \mathrm{~nm}$. In bench-top tests of friction and wear, the oil containing particles in the range of 100 to $200 \mathrm{~nm}$ provided very low friction coefficients of about 0.05 (as opposed to 0.12 for base synthetic oils). During our screening tests, we also studied particle-additive interactions and determined the optimum concentrations at which good lubricity could be achieved. One of the oil blends delivered by our partner exhibited excellent stability and tribological performance at BA concentrations down to $0.1 \mathrm{wt} . \%$. This important finding suggests that our boron-based additives would be cost-effective and, hence, attractive from a commercialization point of view. A few of the oil blends provided by our partner showed some tendency to agglomerate into larger chunks, but the actual particles themselves were in the range of 30 to $50 \mathrm{~nm}$. A significant portion of our activities in the first year of this project was directed toward determining the most effective surfactants and keeping these nanoparticles in a colloidal dispersion with oils. 
In another systematic study under $1 \mathrm{GPa}$ contact pressure and at $100^{\circ} \mathrm{C}$ temperature, reciprocating tests were run to assess the performance of engine oils with and without antifriction and -wear additives. Specifically, in some tests the anti-wear (AW) additive was taken out completely; in another, the friction modifier (FM) was absent; and yet in a third batch, the FM and AW were taken out of the oil samples but the rest of the additives (anti-oxidant, detergent, viscosity improvers, etc.) remained. The objective was to determine if our boron-based additives could provide the same levels or preferably better friction and wear performance than the engine oils with the full additive package.

Table 3 summarizes the results obtained from our test machines. Among the oil samples tested, the mixture with the best performance did not contain the AW additive. Specifically, the friction performance of this boron-additive blend was comparable to that of a fully formulated $5 \mathrm{~W} 30$ engine oil, but its wear was reduced by more than 50\% (see Fig. 21). In the case of the oil sample without FM, the level of wear reduction was more than $17 \%$ (see Fig. 22) when compared to fully formulated engine oil while friction was comparable, presumably due to the very severe contact pressure and high test temperature. For the case of no AW and FM, our boron additives maintained very reasonable friction and wear performance by reducing wear by $45 \%$ with respect to the oil sample without AW and FM. Nevertheless, the wear was $8 \%$ higher than that of the fully formulated 5W30 oil. Overall, optimized boron additives have shown the possibility to replace either AW or FM or both additives from the current engine oils.

Table 3. Friction and wear results and comments on reciprocating tests using various lubricants with and without boric acid additives.

\begin{tabular}{|c|c|c|c|c|c|}
\hline \multirow[b]{2}{*}{ Oil Type } & \multicolumn{2}{|c|}{ No boron additive } & \multicolumn{2}{|c|}{ With boron additive } & \multirow{2}{*}{ Comments (Wear) } \\
\hline & Friction & Wear $(\mu \mathrm{m})$ & Friction & Wear $(\mu \mathrm{m})$ & \\
\hline $\begin{array}{l}\text { Full Synthetic, } \\
5 \text { W30 }\end{array}$ & 0.12 & 148 & 0.10 & 144 & Slightly better \\
\hline $\begin{array}{l}\text { 5W30, without } \\
\text { ZDDP (AW) }\end{array}$ & 0.11 & 347 & 0.11 & 151 & $\begin{array}{l}56 \% \text { reduction in } \\
\text { wear, friction is the } \\
\text { same }\end{array}$ \\
\hline $\begin{array}{l}\text { 5W30, without } \\
\text { MoDTC (FM) }\end{array}$ & 0.11 & 138 & 0.1 & 114 & $\begin{array}{l}17 \% \text { reduction in } \\
\text { wear, friction is } \\
\text { similar }\end{array}$ \\
\hline $\begin{array}{l}\text { 5W30, without } \\
\text { ZDDP and MoDTC }\end{array}$ & 0.11 & 288 & 0.11 & 158 & $\begin{array}{l}45 \% \text { reduction in } \\
\text { wear, friction is the } \\
\text { same }\end{array}$ \\
\hline
\end{tabular}




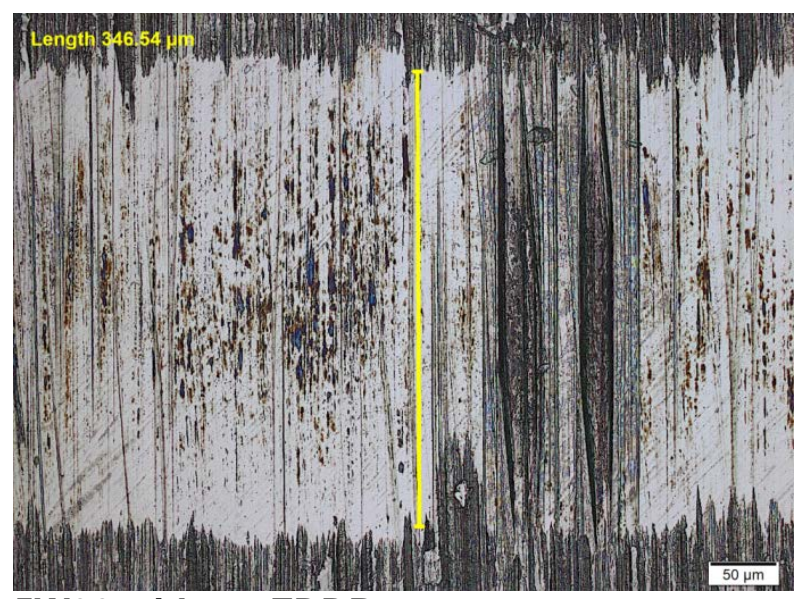

5W30 without ZDDP

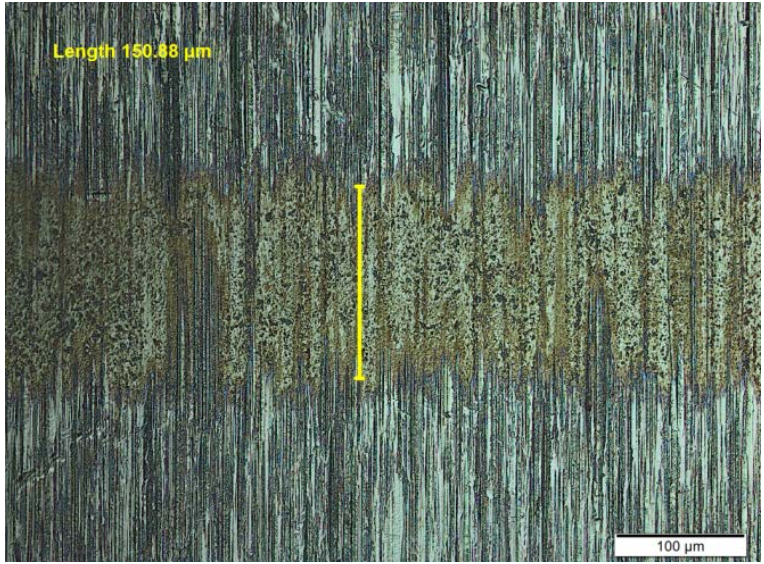

$5 \mathrm{~W} 30$ without $\mathrm{AW}+$ boron additive

Figure 21. Effect of boron additive on wear performance of $5 \mathrm{~W} 30$ engine oil without ZDDP anti-wear additive. The amount of wear from the test of oil without ZDDP (as represented by the wear width) is about $347 \mu \mathrm{m}$ in left image, while wear width for the test of same oil with Argonne boron additive is about $151 \mu \mathrm{m}$ (right). Obviously, without the ZDDP anti-wear additive, rubbing surfaces are unprotected and, hence, vulnerable to wear, as the image on left confirms.

Figures 21 and 22 indicate a very effective boundary film formation on the sliding surfaces, suggesting that boron additives had undergone a tribochemical reaction with these sliding surfaces. We believe that such a boundary film might have been mainly responsible for the dramatic improvements in wear performance of these oils. As discussed above, these tribochemical films mainly consisted of boron and oxygen, which are two of the key elemental ingredients of our nanoparticle boron additives.

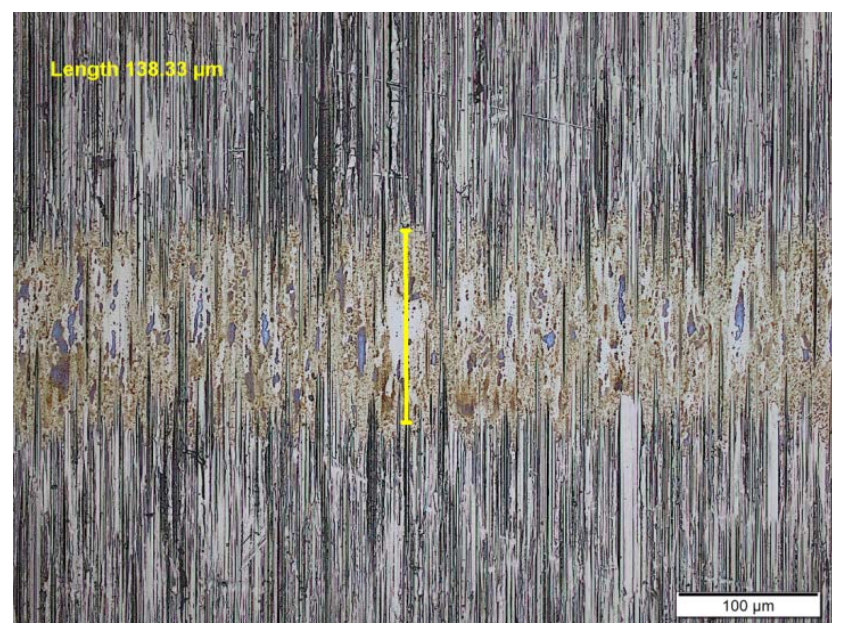

$5 \mathrm{~W} 30$ without friction modifier: $138 \mu \mathrm{m}$

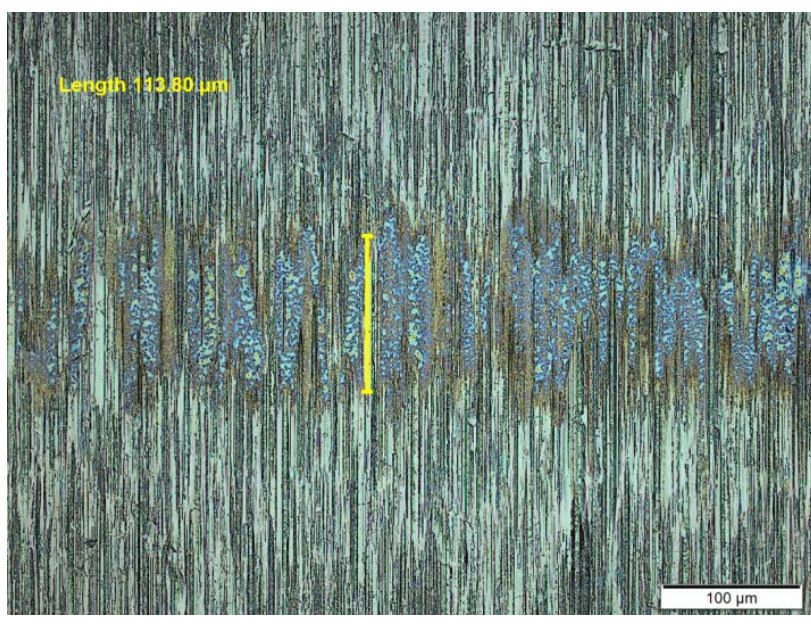

5W30 without friction modifier + ANL additive: $114 \mu \mathrm{m}$

Figure 22. Effect of nanoparticle boron additive on wear performance of $5 \mathrm{~W} 30$ oil without MoDTC anti-friction additive. The amount of wear as represented by the wear width is about $138 \mu \mathrm{m}$ on left image and is from the oil without MoDTC, while the image on right is from the same oil with Argonne nanoparticle boron additive and its wear width is about $114 \mu \mathrm{m}$. Presence of anti-wear additive in this oil blend obviously reduces wear substantially (image on left), but presence of boron additive reduces it further, as shown in the photo on right. 
The TOF-SIMS analysis provided critical information on the extent of tribochemical interactions that occurred during these sliding tests. The general observations from the TOF-SIMS studies were that, with the use of boric acid in partially formulated engine oils, much thicker and hence more protective boundary films had formed (which could explain the extreme resistance of these oils to wear and scuffing, see Table 3). The protective boundary films consisted of large amounts of boron, but some zinc, sulfur, and phosphorus were also detected during these analyses, depending on the type of oil tested. We believe that zinc, sulfur, and phosphorus are mostly coming from the ZDDP additive in the oil, but apparently, our boron-based additives are blending with these in a very synergistic and highly effective manner, i.e., making ZDDP function even better.

We tested both boric acid and boron nitride containing oil blends for up to 4 days and did not observe any degradation in their friction and wear performance. One of the unexpected but very desirable outcomes of these long-duration studies was that our boron-containing oil blends yielded 20 to $30 \%$ lower friction under very slow sliding contact conditions (i.e., $0.01 \mathrm{~m} / \mathrm{s}$ ). Normally, if we run tests with base or fully formulated traditional oils, friction increases due to more direct asperity-asperity collisions at such slow sliding velocities and a diminished hydrodynamic effect. However, in our case, the friction was significantly reduced under such conditions. We believe that the easy shearing nature of the boric acid and boron nitride was perhaps responsible for such behavior. Again, this desirable attribute will have a significant positive impact on the energy efficiency of those mechanical systems that operate under severe boundary regimes. In fact, we noticed significant reductions in friction, which might have resulted from the formation of thicker and more effective boundary films on rubbing surfaces. In the case of boron nitride, boron largely remained as boron nitride and was mixed as nanoscale crystals within the boundary film.

\subsection{Hybrid Boron-MoS 2 Lubrication Studies}

As part of our research activities, we investigated whether a hybrid nanolubrication approach involving the mixing of our boron-based additives with $\mathrm{MoS}_{2}$-based nanolubricants might trigger additional beneficial effects, especially under severe tribological conditions. Accordingly, we included $\mathrm{MoS}_{2}$-based nanolubricants to develop a hybrid boron-MoS $\mathrm{S}_{2}$-based nanolubricant that might collectively provide superior lubricity over a broader range of test conditions. A subcontract was established with the University of Arkansas to pursue this approach. Specifically, the University of Arkansas participants blended and provided a series of nanolubricants that consisted of nanoparticles of $\mathrm{MoS}_{2}$ and boric acid in a carrier oil. The tribological testing (as shown in Table 4) of these hybrid lubricants demonstrated desirable performance, as they together reduced friction considerably under severe sliding conditions in comparison to commercial lubricants without any nanoparticulates. Thus, our joint work has confirmed that a hybrid lubrication approach might also provide significant benefits in terms of much improved friction and wear properties. 
Table 4. Wear performance of a VG220 gear oil with and without $\mathrm{MoS}_{2}$ and boric acid.

\begin{tabular}{|l|l|l|}
\hline Samples & Friction & Wear $(\mu \mathrm{m})$ \\
\hline VG220 & 0.097 & 215 \\
\hline VG220+ 1.0 wt.\% MoS 2 & 0.095 & 182 \\
\hline VG220+ 1.0 wt.\% Boric Acid & 0.099 & 182 \\
\hline $\begin{array}{l}\text { VG220 + 1.0 wt.\% } \mathrm{MoS}_{2}+ \\
\text { Boric Acid } \\
(1: 1 \text { volume ratio) }\end{array}$ & 0.102 & 168 \\
\hline
\end{tabular}

Besides favorable frictional behavior, the hybrid boric acid $\mathrm{MoS}_{2}$ lubricants exhibited superior wear compared to the fully formulated oils. Specifically, it resulted in $30 \%$ reduction in wear despite the very severe nature of these sliding tests.

In an effort to understand the chemical nature of the protective boundary films that resulted from the hybrid nanolubricants, we performed comprehensive surface analytical studies on sliding surfaces. The XPS analysis of the tribofilm in Fig. 23 revealed high concentrations of boron and sulfur in the tribofilm. Also, the presence of molybdenum and oxygen was confirmed. The Mo most likely came from the $\mathrm{MoS}_{2}$, since the Mo content of the steel sample was very low (i.e., less than $1 \mathrm{wt.} \%$ ), while oxygen may have come from the boric acid or tribo-oxidation of $\mathrm{MoS}_{2}$ and/or sliding steel surfaces. Moreover, we found some phosphorus within the sliding wear tracks, which may have been due to ZDDP additives in the commercial oil. These surface studies further confirmed that hybrid nanolubricants form more durable low-friction and -wear protective films and thus provide superior tribological performance.

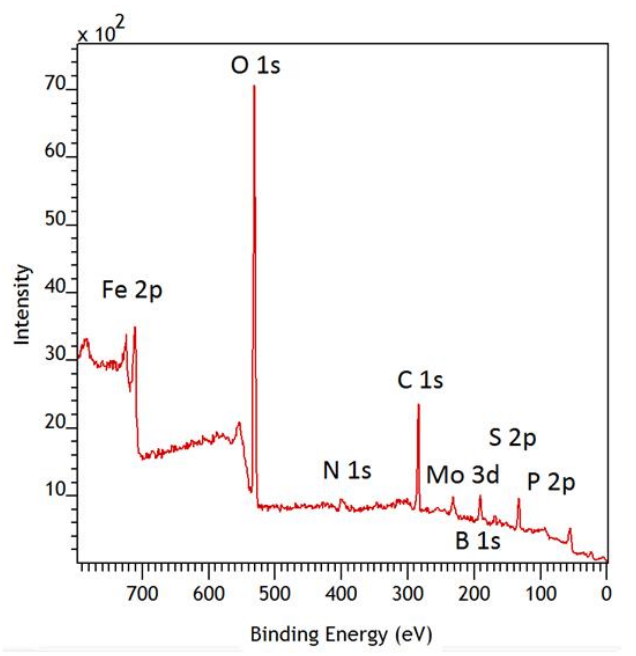

- Elemental Concentration

- C 1s:

-0 1s:

- B 1s:

17.7

- S 2p:

3.2

$-\mathrm{P} 2 \mathrm{p}:$

7.1

- Fe $2 p$ :

9.9

- Mo 3d:

0.8

Figure 23. XPS spectrum and chemical quantification of species within tribofilm that resulted from a hybrid $\mathrm{MoS}_{2}+$ boric acid nanolubricant. 
High resolution XPS of a boron-, sulfur-, phosphorus-, and molybdenum-rich tribofilm revealed important information on the specific details of the tribochemical interactions taking place during sliding. After curve fitting of XPS spectra (as presented in Fig. 24), we determined that the protective tribofilm consisted of complex boron oxides, molybdenum oxides, various molybdenum disulfides and sulfates, and several kinds of phosphates. Since boron oxides and molybdenum disulfides are expected to provide very good anti-friction and -wear performance, this finding was consistent with the tribological data presented in Table 4. Based on these detailed surface analytical studies, we propose a lubrication model illustrating how such tribofilms form and protect sliding surfaces against wear in Fig. 25.
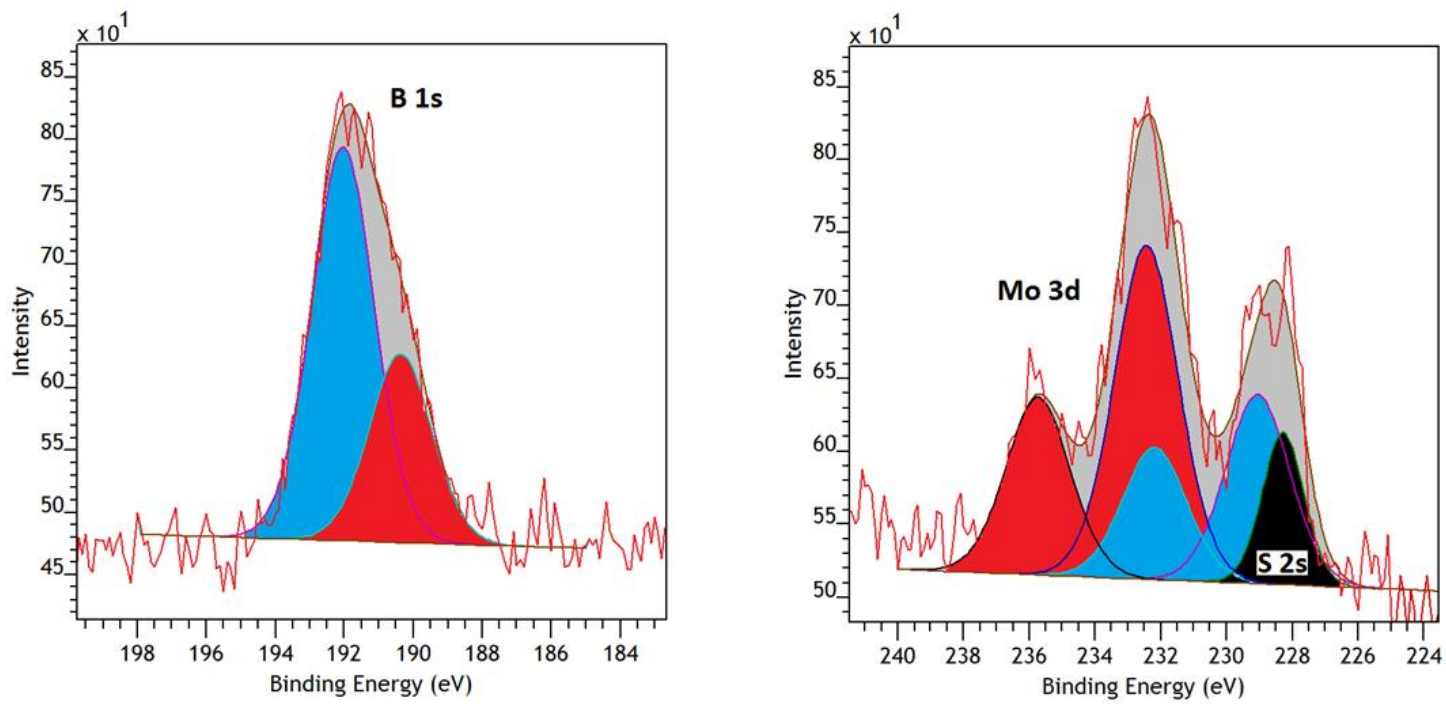

Figure 14. Boron and molybdenum chemical species identified using high-resolution XPS within the tribofilm, which resulted from hybrid $\mathrm{MoS}_{2}+$ boric acid nanolubricants.

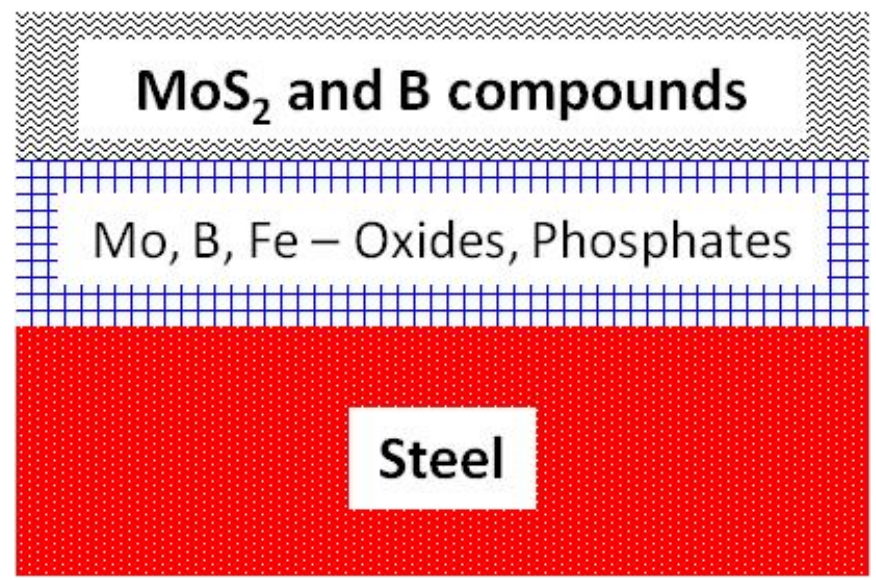

Figure 25. Proposed protective tribofilm model for hybrid $\left(\mathrm{MoS}_{2}+\right.$ boric acid) lubricant on sliding steel surfaces. 


\subsection{Micropitting Tests}

On another front, using a dedicated gear test machine (see Fig. 26), we evaluated the micropitting and wear performance of a commercial 75W90 gear oil with and without any boron additives. Gear oils are made of higher viscosity base oils and contain large amounts of extreme pressure lubrication additives besides anti-friction and -wear additives as in engine oils. There is an urgent need to lower their viscosity, to eliminate some additives due to environmental concerns, and to find more effective extreme pressure additives to confront increasingly harsher operating conditions of gears. Lowering viscosity will reduce churning or hydrodynamic losses and thus increase efficiency.

In tests with fully formulated 75W90 gear oil, the signs of micropitting showed up after about 4 hours of testing and worsened after 15 hours (see Fig. 27). However, in a repeat of the same tests with the same Valvoline gear oil blended with our boron-based lubrication additives, we could not detect any sign of micropit formation even after 15 hours of testing. As can be deduced from Fig. 27, the width of the wear or rolling track was also reduced substantially in the case of boron-additive-containing gear oil. These favorable results were further corroborated by accelerometer traces, which reflect the amount of noise level due to high traction and/or surface micropitting. As shown in Fig. 28, the level of noise recorded during testing of control $75 \mathrm{~W} 90$ oil was much higher than that of the boron-additive-containing 75 W90 oil.

\section{Micropitting Tests (pcs Instruments)}

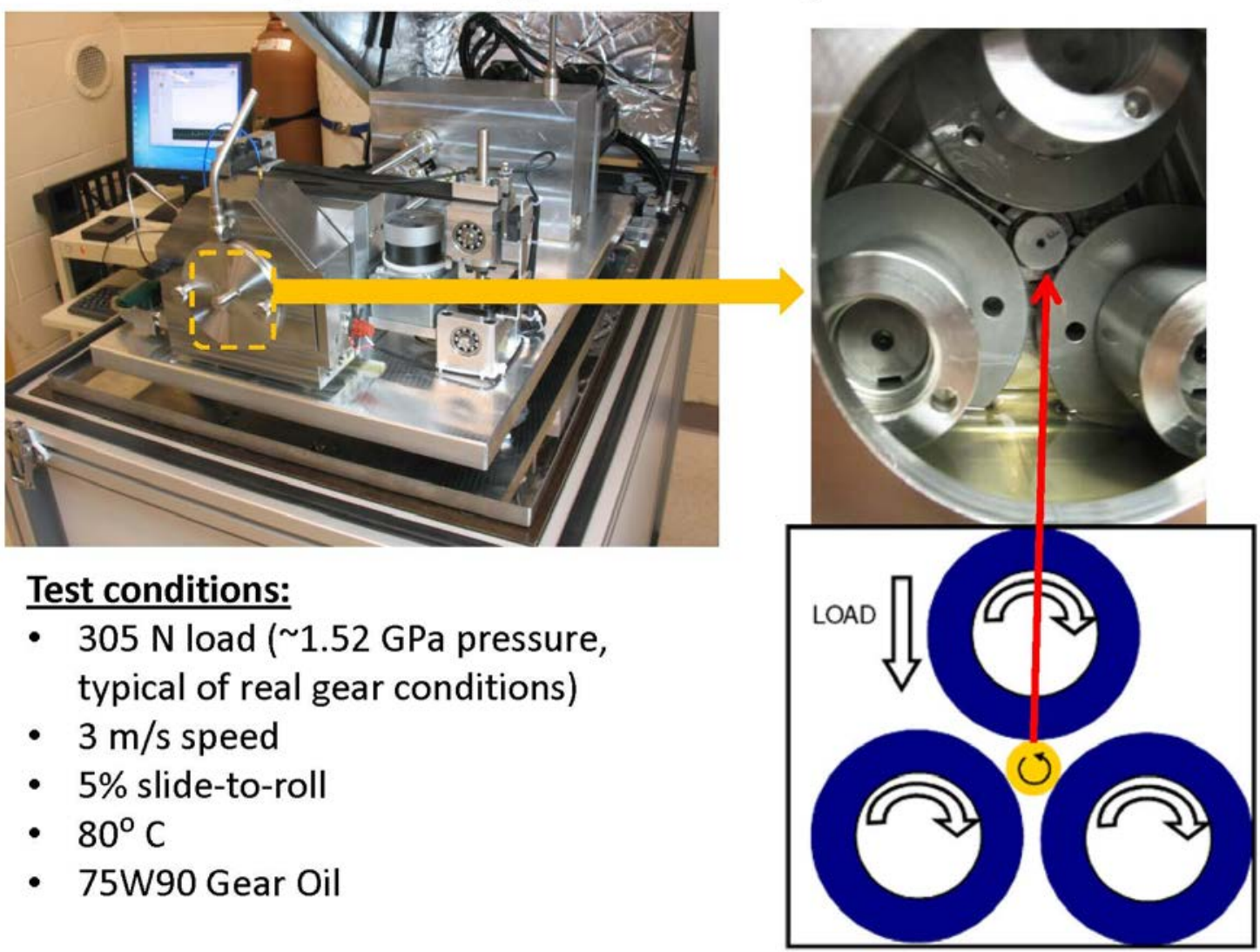

Figure 26. Photo and general layout of the PCS micropitting (gear) test machine and test conditions used in our evaluation. 

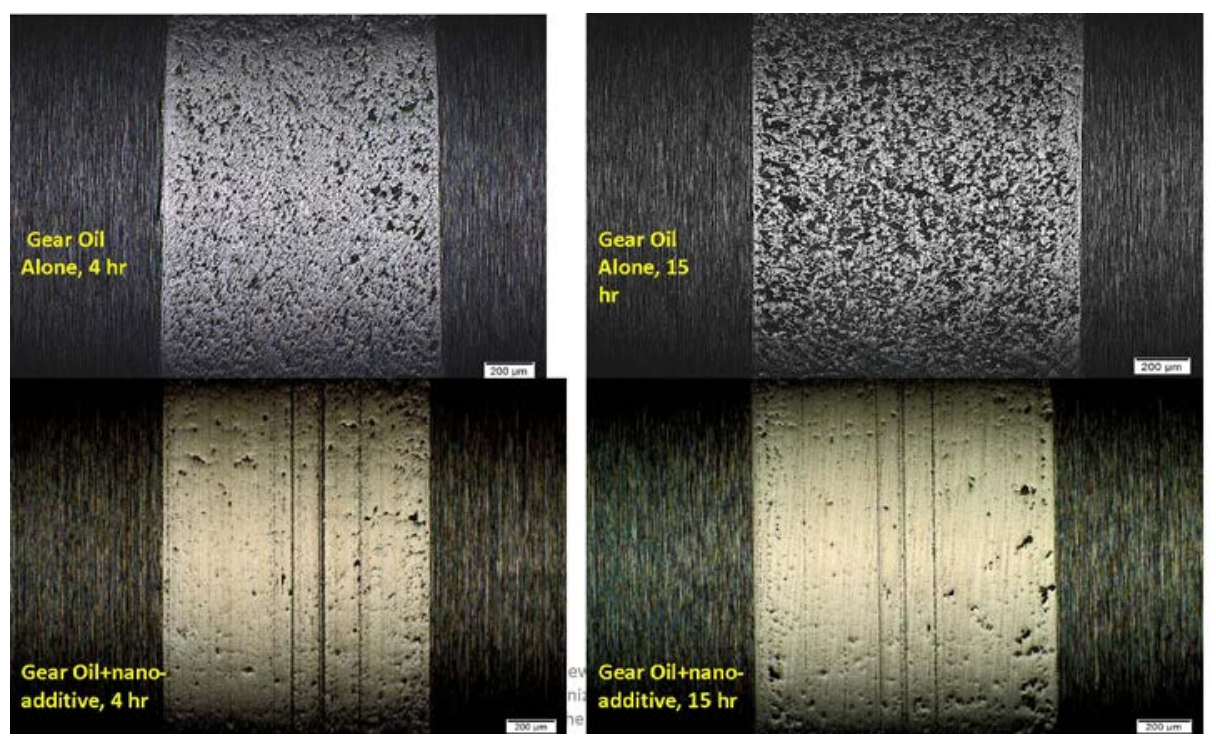

Figure 27. Images of test rollers used in micropitting (gear) tests. Top two images are from Valvoline $75 \mathrm{~W} 90$ gear oil without boron additive, while bottom two images are from boron-containing $75 \mathrm{~W} 90$ oil after 4 and 15 hours of testing. Note that there are numerous pits on top images but almost none in bottom ones, further confirming anti-pitting behavior of our additives.

\section{MPR Test of Gear Oil @ $305 \mathrm{~N}(1.5 \mathrm{GPa})$ \\ 4th hr Run time}

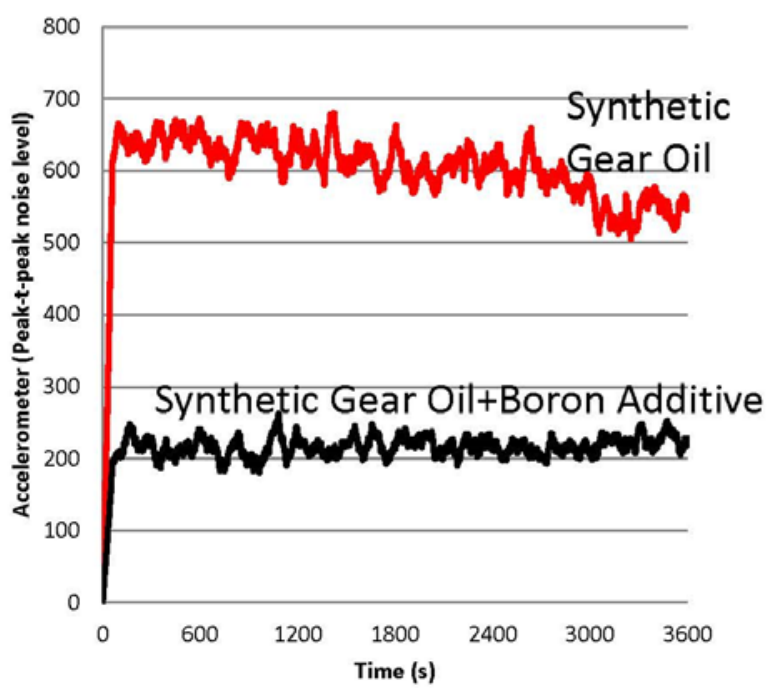

MPR Test of Gear Oil $305 \mathrm{~N}(1.5 \mathrm{GPa})$

15 hrs Test

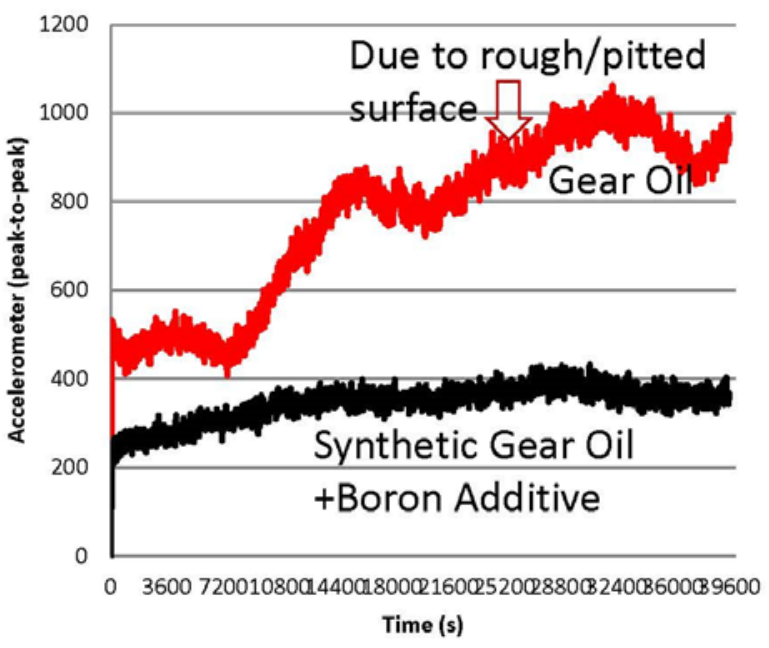

Figure 28. Accelerometer noise levels from Valvoline 75W90 and the same oil blended with our nanoboron additive.

\section{Benefits Assessment}

The boron-based nanolubrication products developed and optimized in this project have demonstrated high potential to substantially improve the friction, wear, and scuffing performance 
of base and formulated oils over a range of test conditions. Optimization of particle size and concentration, as well as the selection of surfactants, was all important for the overall performance of the lubricants and/or additives tested. Boron-based particulate additives considered in this project included boric acid $\left(\mathrm{H}_{3} \mathrm{BO}_{3}\right)$, hexagonal boron nitride ( $\left.\mathrm{h}-\mathrm{BN}\right)$, boron oxide, and borax. As part of this project, we also explored a hybrid $\mathrm{MoS}_{2}$-boric acid formulation for more effective lubrication and reported the results. These products have the potential to reduce the amount of anti-friction and -wear additives as well as synergistically work with oil additives to significantly improve the durability and long-term performance of many types of machine components that are subjected to the sliding, rolling, reciprocating, and rotating motions that occur in the transportation, manufacturing, oil and gas industry; in chemical and petroleum plants; and in construction, agriculture, and earth-moving operations. Overall, these lubrication additives have the potential to provide significant energy, environmental, and economic benefits to many industrial sectors by increasing energy efficiency, productivity, and environmental compatibility and by lowering operational and maintenance costs.

Reduction in friction and wear in mechanical components is expected to translate into higher efficiency, longer durability, and lower emissions in transportation and other cross-cutting industrial applications. Overall, this project has clearly demonstrated the significant beneficial effect of particulate additives on limiting friction- and wear-related losses. Improved resistance to scuffing, abrasion, and micropitting is expected to increase resistance to degradation in severe industrial operations involving forming, machining, rolling, rotating, and sliding. By increasing component life, these lubricants will reduce the need for frequent part replacement and, hence, curtail the consumption of energy that is needed for the manufacturing of new parts. Realizing such a beneficial impact, industrial partners are seriously considering licensing this technology pending cost-benefit analysis and environmental impact studies.

\section{Publications}

Our project has resulted in 6 archival publications and 17 technical presentations, listed below.

\section{Journal Articles:}

1. A. Greco, K. Mistry, V. Sista, O. Eryilmaz, and A. Erdemir, "The effect of boron based surface treatment and nano-particle lubricant additives on friction and wear behavior for wind energy applications," Wear, 271 (2011) 1754-1760.

2. K. Holmberg, P. Andersson, and A. Erdemir, "Global energy consumption due to friction in passenger cars," Tribology International, 47 (2012) 221-234.

3. N. Matsumoto, K. Mistry, J.-H. Kim, O. L. Eryilmaz, A. Erdemir., H. Kinoshita, and N.Ohmae, "Friction-reducing properties of onion-like carbon under high contact pressure in liquid lubricant", Tribology - Materials, Surfaces, and Interfaces, 6 (2012) 116-120.

4. J.-H. Kim, K. K. Mistry, N. Matsumoto, V. Sista, O. L. Eryilmaz and A. Erdemir, "Effect of surfactant on the tribological performance and tribochemistry of boric acid based colloidal lubricants," Tribology - Materials, Surfaces, and Interfaces, 6 (2012) 134-141.

5. K. Holmberg, P. Andersson, and A. Erdemir, "Friction and energy consumption in passenger cars", in Proceedings of LUBMAT 2012 Conference, Bilbao, Spain, June 5-8, 2012. 
6. K. K. Mistry, A. Morina, A. Erdemir, and A. Neville, "Tribological performance of EP lubricants with phosphorus-based additives," Tribology Transactions, 54(2013)645-651.

\section{Presentations:}

1. A. Erdemir and L. Ajayi, "Advances in surface and lubrication engineering and sciences for tribological performance enhancement," Presented to Oakland University, Rochester, MI, October 19, 2011.

2. A. Erdemir and A. Greco, "Advanced surface treatments and nanolubricants," NREL Wind Turbine Tribology Seminar, Boulder, CO, November 16-18, 2011.

3. A. Greco, K. Mistry, V. Sista, and A. Erdemir, "The effect of boron based surface treatment and nano-particle lubricant additives on friction and wear behavior for wind energy applications," Presented at the 18th International Conference on Wear of Materials, Philadelphia, PA, April 3-7, 2011.

4. A. Erdemir, "Recent advances in boron-based lubricants for energy saving applications in engines," Presented at the 17th International Symposium on Boron, Borides and Related Materials, Istanbul, Turkey, September 11-17, 2011.

5. A. Erdemir, "Boron and its compounds for lubrication," Presented to Rio Tinto Minerals, Denver, CO, June 2, 2010.

6. A. Erdemir, "Progress in low-dimensional solid lubrication additives for demanding tribological applications," Presented at ASME/STLE Joint Tribology Conference, Denver, CO, October 8-10, 2012.

7. A. Erdemir, A. Greco, and K. Mistry, "Novel boron-based nano-lubricants for mitigating wear and micropitting failures in gearboxes," Presented at the 67th Annual Meeting of the Society of Tribologists and Lubrication Engineers, St. Louis, MO, May 7-10, 2012.

8. A. Greco, K. Mistry, V. Sista, and A. Erdemir, "The effect of boron based surface treatment and nano-particle lubricant additives on friction and wear behavior for wind energy applications," Presented at the 18th International Conference on Wear of Materials, Philadelphia, PA, April 3-7, 2011.

9. A. Erdemir and J. M. Martin, "Nano-colloidal lubrication: Promise and pitfalls," Presented at the Annual Meeting of Society of Tribologists and Lubrication Engineers, Atlanta, GA, May 15-19, 2011.

10. K. Mistry, E. Briggs, J. Kim, O. L. Eryilmaz, and A. Erdemir, "Tribological studies and understanding lubrication mechanism of boron additives," Presented at the Annual Meeting of Society of Tribologists and Lubrication Engineers, Atlanta, GA, May 15-19, 2011.

11. J. H. Kim, K. Mistry, H. Chipman, O. L. Eryilmaz, and A. Erdemir, "Effects of surfactants on dispersibility and tribological performance of nano-lubricants under severe tribological conditions," Presented at the 2010 ASME/STLE International Joint Tribology Conference, San Francisco, CA, October 18-20, 2010. 
12. K. Mistry, N. Matsumoto, J. H. Kim, H. Chipman, O. L. Eryilmaz, and A. Erdemir, "Tribochemistry and lubricity of vegetable based colloidal lubricants under severe tribological conditions," Presented at the 2010 ASME/STLE International Joint Tribology Conference, San Francisco, CA, October 18-20, 2010.

13. W. Zhang, D. Demydov, A. P. Malshe, K.. Mistry, and A. Erdemir, "Fundamental understanding of the synergistic effect of boron- $\mathrm{MoS}_{2}$ nanoparticulate hybrid system," Presented at the 2010 ASME/STLE International Joint Tribology Conference, San Francisco, CA, October 18-20, 2010.

14. K. Mistry, A. Erdemir, W. Zhang, D. Demydov, and A. Malshe, "Tribolochemical interaction of boron and $\mathrm{MoS}_{2}$ based nano-colloidal lubrication under severe tribological conditions," Presented at the 2010 ASME/STLE International Joint Tribology Conference, San Francisco, CA, October 18-20, 2010.

15. K. Mistry, N. Matsumoto, H. Chipman, and A. Erdemir, "Tribological performance and tribochemical characterization of different boron-based nano-lubricants," Presented at the 65th Annual Meeting of the Society of Tribologists and Lubrication Engineers, Las Vegas, NV, May 16-20, 2010.

16. K. Mistry, H. Chipman, N. Matsumoto, and A. Erdemir, "Understanding lubrication mechanism of nano-boron nitride," Presented at the 65th Annual Meeting of the Society of Tribologists and Lubrication Engineers, las Vegas, NV, May 16-20, 2010.

17. H. Chipman, N. Matsumoto, K. Mistry, O.L. Eryilmaz, and A. Erdemir, "Effectiveness of various surfactants on the dispersion of sub-micron size boric acid particles in oils," Presented at the 65th Annual Meeting of the Society of Tribologists and Lubrication Engineers, Las Vegas, NV, May 16-20, 2010.

\section{Conclusions}

The primary objective of this project was to develop novel boron-based colloidal lubrication additives and to optimize and verify their performance under boundary-lubricated sliding conditions. We also tackled problems associated with scale-up, colloidal dispersion, and blending particles with base and formulated oils. Other important issues dealt with in the project were determination of optimum particle size and concentration and the compatibility of boronbased particles with various base fluids and/or additives. Our team members (Valvoline, Primet, and the University of Arkansas) worked collaboratively to develop and optimize the boron-based lubrication additives. Argonne acted as a lead and performed most of the bench-scale friction and wear tests to evaluate the performance of these additives.

Boron-based particulate additives considered in this project included boric acid $\left(\mathrm{H}_{3} \mathrm{BO}_{3}\right)$, hexagonal boron nitride ( $\mathrm{h}-\mathrm{BN}$ ), boron oxide, and borax. Boric acid and boron nitride along with a hybrid boric acid and molybdenum disulfide showed significant improvements in friction, wear, and scuffing performance of tested samples. Systematic surface analytical studies revealed a strong tribochemical interaction leading to the formation of highly protective boundary films on rubbing surfaces. Overall, the findings of this project clearly demonstrated that boron-based nanomaterials used as colloidal additives in oil reduce frictional losses (hence, achieve greater energy efficiency) and improve resistance to wear and scuffing (thus increase durability). 
Accordingly, the outcome of this project may have far-reaching implications for mechanical systems in the transportation and manufacturing sectors by improving efficiency, durability, and environmental compliance. In sum, the project met its objectives, and the technology has been brought to a level where industry can take over and implement for large-scale practice.

\section{Recommendations}

Many other industrial applications in manufacturing, power generation, mining, aerospace, making or shaping of ferrous/non-ferrous products can potentially benefit from the use of the lubrication technology developed under this project. In particular, moving mechanical parts and components in these applications that are lubricated by conventional lubricants may achieve much higher performance, efficiency, and durability with the use of the boron-based lubricants. Therefore, it is recommended to further explore the potential of these novel lubricants with those companies that are active in other industrial sectors besides transportation. 


\section{References}

1. P. Jost, "Tribology micro and macro economics: A road to economic savings," Tribology and Lubrication Technology, 61 (2005) 18-22.

2. W. J. Bartz, "Lubricants and lubrication engineering: A review," Wear, 49 (1978) 1-18.

3. M. I. De Barros, I. Raoult, T. Le Mogne, J. M. Martin, M. Kasrai, and Y. Yamada, "Friction reduction by metal sulfides in boundary lubrication studied by XPS and XANES analyses", Wear, 254 (2003) 863-870.

4. H. A. Spikes, "Low- and zero-sulphated ash, phosphorus and sulphur anti-wear additives for engine oils," Lubrication Science, 20 (2008) 103-136.

5. J.-M. Martin and N. Ohmae, eds., Nanolubricants, Wiley, New York, 2008.

6. A. Verma, W. Jiang, H. Abu Safe, W. Brown, and A. Malshe, "Tribological behavior of deagglomerated active inorganic nanoparticles for advanced lubrication," Tribology Transactions, 51 (2008) 673.

7. Y. Kimura, T. Wakabayashi, K. Okada, T. Wada, and H. Nishikawa, "Boron nitride as a lubricant additive," Wear, 232 (1999) 199-206.

8. A. Erdemir, "Tribological properties of boric acid and boric-acid-forming surfaces. Part I: Crystal chemistry and mechanism of self-lubrication of boric acid," Lubr. Eng., 47 (1991) 168-172.

9. A. Erdemir, G. R. Fenske, R. A. Erck, F. A. Nichols, and D. E. Busch, "Tribological properties of boric acid and boric-acid-forming surfaces. Part II. Mechanisms of formation and self-lubrication of boric acid films on boron- and boric oxide-containing surfaces," Lubr. Eng., 47 (1991) 179-185.

10. K. L. Kreuz, R. S. Fein, and M. Dundy, "EP films from borate lubricants," ASLE Trans. 10 (1967) 67-76.

11. B. A. Baldwin, "Relative antiwear efficiency of boron and sulfur surface species," Wear 45 (1977) 345-353.

12. W. Liu, Z. Jin, and Q. Xue, "The performance and antiwear mechanism of S-containing organic borate as an oil additive," Lubr. Sci. 7 (1994) 49-60.

13. J. Yao, "Antiwear function and mechanism of borate containing nitrogen," Tribol. Int. 30 (1997) 387-389.

14. C. Y. Zhi, Y. Bando, C. C. Tan, and D. Golberg, "Effective precursor for high yield synthesis of pure BN nanotubes," Sol. State Comm. 135 (2005) 67-70.

15. Chemical Market Reporter, vol. 267, no. 1 (April 2006).

16. A. Erdemir, "Boron-based solid nanolubricants and lubrication additives," in Nanolubrication, eds., J.-M. Martin and N. Ohmae, Wiley, New York, 2008, pp. 203-223. 


\section{Argonne}

Energy Systems Division

Argonne National Laboratory

9700 South Cass Avenue, Bldg. 362

Argonne, IL 60439-4815

www.anl.gov 
